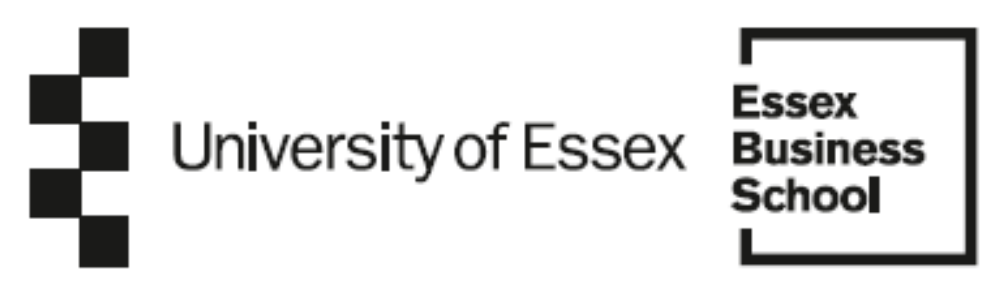

\author{
Essex Finance Centre \\ Working Paper Series
}

"Commodity price uncertainty comovement: Does it matter for global economic growth?"

"Laurent Ferrara, Aikaterini Karadimitropoulou, Athanasios Triantafyllou" 


\title{
Commodity price uncertainty comovement: Does it matter for global economic growth?*
}

\author{
Laurent Ferrara ${ }^{\dagger}$ Aikaterini Karadimitropoulou ${ }^{\ddagger}$ Athanasios Triantafyllou ${ }^{\S}$
}

December 28, 2021

\begin{abstract}
Global economic activity is surrounded by increasing uncertainties from various sources. In this paper, we focus on commodity prices and estimate a global commodity uncertainty factor by capturing comovement in volatilities of major agricultural, metals and energy commodity markets through a group-specific Dynamic Factor Model. Then, by computing impulse response functions estimated using a small-scale Structural VAR model, we find that an increase in the common commodity price uncertainty results in a substantial and persistent drop in investment and trade, for a set of emerging and advanced economies. We also show that a global commodity uncertainty shock is more detrimental for short- and long-term economic growth than usual financial and economic policy uncertainty shocks. Last, our methodology turns out to be an efficient way to disentangle "good" and "bad" macroeconomic effects of oil price uncertainty: when an oil price uncertainty shock is common to all commodities, then the macroeconomic effect is likely to be negative, similar to a global demand shock. However, when the uncertainty shock is only specific to the oil market, the short-run effect tends to be positive.
\end{abstract}

Keywords: Commodity uncertainty, dynamic factor model, investment, trade flows, comovement, uncertainty shocks.

JEL Classifications: C51, C53, Q02

\footnotetext{
*We would like to thank Giovanni Caggiano, Domenico Giannone, Lutz Kilian, Lise Patureau, Celine Poilly and Fabien Tripier for their useful comments and suggestions, as well as participants of the International Symposium on Forecasting 2021, Univ. of Nantes econometric workshop 2021, University of Essex seminar, IMF-Institute of Capacity Development seminar, IIF workshop on Forecasting in a changing environment in Univ. Autonoma de Madrid and SNDE 2021 workshop for young researchers. All the remaining errors are ours. Laurent Ferrara acknowledges financial support from the French ANR (DEMUR research project ANR-20-CE26-0013)

†SKEMA Business School - University Côte d'Azur \& CAMA, Australian National University, laurent.ferrara@skema.edu

‡University of Piraeus, akaradi@unipi.gr

${ }^{\S}$ ESSEX Business School, a.triantafyllou@essex.ac.uk
} 


\section{Introduction}

The theory of investment under uncertainty predicts that higher uncertainty increases firms' real option to wait for uncertainty resolution and ultimately leads to postponement of investment (Bernanke, 1983; Pindyck, 1990; Pindyck, 2004). A large and growing body in the macroeconomics literature has identified the dampening effect of economic uncertainty shocks on various economic variables (see for example Bloom et al., 2007; Bloom, 2009; Carrière-Swallow and Cespedes, 2013; Jurado et al., 2015; Leduc and Liu, 2016; Baker et al., 2016; Caldara et al., 2016; Basu and Bundick, 2017; among others). For example, Bloom (2009) points out that uncertainty shocks (proxied by spikes in the VXO index) result in a subsequent decrease in US industrial production growth. Also, by comparing advanced and emerging countries, Carrière-Swallow and Cespedes (2013) find that shocks in the VXO index have a significant dampening effect on investment growth in emerging countries, much larger than in major advanced economies. Another strand of the literature focuses on trade and identifies the significant contractionary effect of uncertainty shocks on international trade activity (Feng et al., 2017; Gervais, 2018; Handley, 2014; Handley and Limao, 2015, 2017; Novy and Taylor, 2020; Tam, 2018).

However, it turns out that uncertainty can be generated by various sources. In the wake of the seminal paper by Bloom (2009), it is often assumed that global uncertainty is related to uncertainty in financial markets as proxied by the VXO. More recently, macroeconomic uncertainty has gained importance, for example in the paper of Jurado et al. (2015) in which uncertainty is measured by squared deviations of a set of macroeconomic variables with respect to their conditional expectations stemming from an econometric model (see also Scotti, 2016, for alternative macroeconomic uncertainty measures). Uncertainty can also be generated by policymakers through the implementation of some economic policies (i.e., monetary, fiscal or trade policies). One of the recent examples is the large increase of tariffs on some goods coming from China by the Trump administration that generated an uncertainty spike in the global trade with negative effects on global GDP growth by up to 0.75 pp in 2019 (see Ahir et al., 2019). In this respect, Baker et al. (2016) have developed a number of Economic Policy 
Uncertainty (EPU) indexes with the aim of capturing the uncertainty due to economic policies around the globe. The main idea on which those indexes are built is to count some specific words appearing in newspapers of a given country. Another specific source of uncertainty that has been widely considered in the empirical literature is related to the large variations that can be seen in oil prices. Against this background, it is generally assumed that oil price uncertainty is proxied by oil price volatility. The recent oil-macroeconomics literature has put some emphasis on the significant recessionary effect of oil price uncertainty shocks on U.S. economic activity (Ferderer, 1996; Guo and Kliesen, 2005; Elder and Serletis, 2010; Jo, 2014; Rahman and Serletis, 2011; Elder, 2018). For example, Elder and Serletis (2010) show that oil price uncertainty (estimated through a GARCH-type model) has a significant and long-lasting dampening effect on U.S. economic activity. In addition, Ferderer (1996) shows that oil price volatility contains a significant part of the explanatory power of asymmetric oil price shocks on U.S. economic activity. Guo and Kliesen (2005) show that oil price volatility (approximated by the quarterly realized variance of the daily returns of WTI crude oil prices) contains extra predictive power on U.S. output when compared to that of asymmetric oil price shocks. Overall, the consensus in the relevant literature tends to show that oil price uncertainty shocks have a significant recessionary effect on economic activity (see Baumeister and Kilian, 2016, for a more moderate view on the macroeconomic effects of oil price uncertainty for the U.S. economy). One of the few exception is the paper by Punzi (2019) who theoretically and empirically shows that an oil price uncertainty shock is likely to generate short-term positive outcome. Indeed, the channel is that, facing possible increase in future prices, households and companies tend to increase today their consumption of energy. This idea that positive economic outcomes can be generated from an uncertainty shock is referred to as the growthoption channel by Bloom (2014). This has been also considered by Segal et al. (2015) and Forni et al. (2021) who disentangle "good" and "bad" outcomes of uncertainty shocks: a "good" uncertainty shock results in positive economic growth, while a "bad" uncertainty shock leads to the opposite.

However, to our knowledge, empirical evidence on the macroeconomic impact of nonoil commodity uncertainty shocks, like agricultural or metals' uncertainty shocks, is rather 
scarce. We can only refer to the work of Tran (2021), who examines the combined effect of oil and non-oil price uncertainty shocks on economic activity and shows that a trade-weighted commodity price uncertainty index (constructed using a broad set of agricultural, metals and energy commodity prices) has a significant recessionary effect on Australian economic activity, aggregate consumption and export growth. With our paper, we attempt to fill this gap in the relevant literature.

Independently, there is a large and growing body in the literature on commodity markets as a whole showing that commodity prices tend to move together and that commodity price shocks account for a large share of business cycle fluctuations, especially for developing countries $^{1}$. In particular, Delle Chiaie et al. (2021) have pointed out the significant linkages between commodity price comovement and global demand conditions by showing, using a narrative approach, that a latent common factor capturing comovement in a large cross-section of commodity prices is closely related to changes in global demand (see also Alquist et al., 2020). Using this narrative approach they also show that movements in specific groups of commodity prices, such as agricultural, energy and metals, are more likely to be related to supply factors in the concerned sectors. Also, Fernandez et al. (2017) show that unexpected changes in global commodity price shocks account for more than one third of global output fluctuations, while Fernández et al. (2018) find that commodity price fluctuations are significant drivers of macroeconomic fluctuations in small emerging market economies.

In this paper, we aim at assessing the macroeconomic effects of common uncertainty shocks in commodity prices, for both advanced and emerging markets. In this respect, we compute the comovement in uncertainty contained in major agricultural (corn, cotton, soybeans, wheat), metals (copper, gold, silver, platinum) and energy (crude oil, heating oil, gasoline, petroleum) commodity prices. As usual in this literature, we measure uncertainty as the quarterly realized variance of the daily returns of those individual commodity prices, meaning that throughout this paper we will indifferently use the words uncertainty and volatility. Our econometric methodology relies on a two-step procedure. In a first step, we extract

\footnotetext{
${ }^{1}$ See for example Pindyck and Rotemberg, 1990; Frankel and Rose, 2010; Byrne et al., 2013; Fernandez et al., 2017; Drechsel and Tenreyro, 2018; Fernandez et al., 2018, Gruber and Vigfusson, 2018; Alquist et al., 2020; Poncela et al., 2020; or Delle Chiaie et al., 2021
} 
the common uncertainty by estimating a Bayesian Dynamic Factor Model (DFM) with a group-specific structure, as put forward by Kose et al. (2003). This generalization of the standard DFM, as proposed for example in Doz et al. (2011), enables to estimate two factors: (i) a global commodity price uncertainty factor, which captures comovement across all commodity price uncertainty series and (ii) a group-specific commodity uncertainty factor, which captures uncertainty comovement for each group-specific commodity, namely, agriculture, metals and energy markets. In a second step, for each advanced and emerging country in our sample, uncertainty factors are sequentially incorporated into a small-scale Structural VAR (SVAR) model, that also integrates inflation, policy interest rates and a relevant macroeconomic variable. As macroeconomic variables, we mainly focus here on business investment and international trade, while GDP and household consumption will be also considered as additional results. Impulse response functions (IRFs) are then estimated to trace the dynamic impact of uncertainty shocks on each variable. Aggregated results are presented for advanced and emerging countries as a whole.

Our results provide a rich body of evidence about the role of global commodity price uncertainty on the macroeconomic activity of both advanced and emerging countries and extend the empirical research in several directions. First, we find that a global commodity uncertainty shock depresses investment and trade (exports) in both emerging and advanced economies. Those results are the first to point out evidence of a negative dynamic impact of global commodity price uncertainty shocks on international trade and provide further insights on the recent theoretical findings of Gervais (2018) and Novy and Taylor (2020) who highlight the possible mechanisms through which uncertainty shocks lead to contractions in international trade. In addition, we also show evidence of a negative dynamic impact of commodity uncertainty shocks on GDP and household consumption. Second, we carry out a benchmark analysis and compare our results with dynamic responses of popular uncertainty indexes, namely the VIX and EPU indexes. It turns out that our global commodity uncertainty shock leads to a stronger and more persistent negative response of investment and exports. We provide here a new set of results suggesting that uncertainty on commodity prices is more detrimental on short-run economic activity than financial and economic policy uncertainty 
measures. Third, unlike Carrière-Swallow and Cespedes (2013), who find a bounce-back effect in investment of advanced economies after a financial uncertainty shock (proxied by the VIX), we do not find any evidence of a bounce-back after a global commodity uncertainty shock, meaning that this type of shock leads to a long-run impact on the level of investment and thus on potential growth, through capital accumulation. In this respect, global uncertainty commodity shocks are more detrimental for long-run economic activity than financial and economic policy uncertainty measures. Fourth, we separately examine the macroeconomic impact of the group-specific commodity uncertainty factors, namely agricultural, metals and energy, once the global component has been removed and accounted for by the global factor. A striking result is that energy-specific uncertainty shocks tend to have short-run positive effects on economic activity, as measured by growth in investment, exports, GDP and consumption, in line with the theoretical results of Punzi (2019) and empirical results of Mohn and Misund (2009). Our approach appears thus to be an efficient way to disentangle "good" and "bad" macroeconomic effects of oil price uncertainty. Indeed, it turns out that when a rise in oil price uncertainty is common to all commodities, then the macroeconomic impact is likely to be negative, as generally put forward in the literature. However, when this increase in uncertainty is specific to the oil market, then the macroeconomic effect tends to be positive in the short run. Overall, by comparing IRFs of inflation and real variables, we highlight that global uncertainty shocks that simultaneously affect all commodities are likely to reflect global demand uncertainty. This is in line with the analysis put forward by Delle Chiaie et al. (2021) when dealing with the level of commodity prices and with the findings of Leduc and Liu (2016) showing that uncertainty shocks are essentially aggregate demand shocks.

The rest of the paper is structured as follows. In Section 2 we describe the methodology that we use, including the dataset, the Dynamic Factor Model that we estimate to measure global and commodity-group uncertainty, as well as the SVAR models used to assess responses to uncertainty shocks. Section 3 presents the empirical results and Section 4 focuses on disentangling "good" and "bad" oil price uncertainty shocks. Finally, Section 5 concludes. 


\section{Methodology}

\section{$2.1 \quad$ Data}

We proxy commodity uncertainty with volatility measures based on daily data of commodity futures prices. We focus on futures prices as they tend to reflect expectations about the future commodity price evolutions, in the vein of the VIX financial uncertainty index. Following the standard approach in the literature on commodity futures, we take the nearest maturity commodity futures contracts which proxy for the spot price. We obtain daily series for the GSCI nearby commodity futures prices from Datastream, for agricultural (corn, cotton, soybeans, wheat), metals (copper, gold, silver, platinum) and energy (crude oil, heating oil, petroleum, gasoline), that is $n=12$ series. The daily commodity futures dataset covers the period from January 1988 to January 2017.

We estimate commodity price uncertainty for commodity $i$, with $i=1 \ldots, n$, as the quarterly realized variance of the daily returns of the commodity prices according to Equation (1) for a given quarter $t$ :

$$
R V_{i, t}=\frac{252}{T} \sum_{d=1}^{T}\left(r_{t, d}^{i}-r^{i}\right)^{2},
$$

where $T$ is the number of daily observations within the quarter $t, r_{t, d}^{i}$ are the daily growth rates of any commodity $i$ within the quarter $t$ and $r^{i}$ is the average growth rate within the quarter $t$. The realized variances $R V_{i, t}$ are multiplied by 252 (the number of trading days during one calendar year) so that they can be annualized. Table (1) contains the correlation matrix, which shows positive and relatively high correlation coefficient values within the dataset. The average correlation across all 12 commodities realised variance is $50 \%$. Importantly, the correlation between commodity volatility series is higher within the same commodity group (e.g. the correlations within the realised variances of energy is over $90 \%$ and that of agriculture and metals commodities is over 60\%). We also performed the Augmented Dickey-Fuller test and we reject the hypothesis of a unit root for all the realised variance series.

As regards macroeconomic data, we obtain domestic quarterly series for aggregate private investment, consumer price indexes, industrial production indexes, private consumption 
Table 1: Correlation Matrix for the Agricultural, Energy and Metals Commodity Markets Dataset (1988Q12016Q4)

\begin{tabular}{|c|c|c|c|c|c|c|c|c|c|c|c|c|}
\hline & Corn & Cot. & Soy. & Wheat & Crude & Heat. & Petr. & Gasl. & Сорр. & Gold & Plat. & Silv. \\
\hline Corn & 1.00 & & & & & & & & & & & \\
\hline Cotton & 0.62 & 1.00 & & & & & & & & & & \\
\hline Soybeans & 0.76 & 0.55 & 1.00 & & & & & & & & & \\
\hline Wheat & 0.75 & 0.62 & 0.59 & 1.00 & & & & & & & & \\
\hline Crude & 0.26 & 0.27 & 0.24 & 0.22 & 1.00 & & & & & & & \\
\hline Heating & 0.14 & 0.22 & 0.19 & 0.13 & 0.93 & 1.00 & & & & & & \\
\hline Petroleum & 0.27 & 0.29 & 0.26 & 0.23 & 0.99 & 0.96 & 1.00 & & & & & \\
\hline Gasoline & 0.36 & 0.40 & 0.36 & 0.28 & 0.91 & 0.91 & 0.94 & 1.00 & & & & \\
\hline Copper & 0.55 & 0.39 & 0.42 & 0.43 & 0.41 & 0.30 & 0.42 & 0.50 & 1.00 & & & \\
\hline Gold & 0.58 & 0.40 & 0.45 & 0.50 & 0.46 & 0.37 & 0.47 & 0.54 & 0.63 & 1.00 & & \\
\hline Platinum & 0.57 & 0.41 & 0.56 & 0.47 & 0.48 & 0.39 & 0.50 & 0.53 & 0.53 & 0.72 & 1.00 & \\
\hline Silver & 0.62 & 0.51 & 0.44 & 0.54 & 0.35 & 0.22 & 0.35 & 0.42 & 0.67 & 0.81 & 0.59 & 1.00 \\
\hline
\end{tabular}

expenditure, real GDP, exports and the policy rate from the CEIC database. The only exemption is the Brazil policy rate series which is downloaded from IMF database. All macroeconomic variables are expressed in million USD at 2011 prices and we focus on a balanced dataset of 12 advanced and 12 emerging economies. We remove the seasonal variation of the macro-series using the Dagum (1978) X-11 ARIMA method. We then compute the quarterly growth rates for all the seasonally adjusted macroeconomic series (except for the policy rate, which is used in levels). The dataset covers the period from 1988q1 to $2016 \mathrm{q} 4^{2}$.

\subsection{A Commodity-Specific Dynamic Factor Model}

Our objective is to extract a common component from our set of $n=12$ commodity realized volatility series, while accounting for the specific sectoral form of the database split into three groups: (i) agricultural (corn, cotton, soybeans, wheat), (ii) metals (copper, gold, silver, platinum) and (iii) energy (crude oil, heating oil, petroleum, gasoline) volatilities. Against this background, a Dynamic Factor Model (DFM) with hierarchical structure as put forward by Kose et al. (2003), has proved useful, as shown for example by Karadimitropoulou and Leon-Ledesma (2013), Miranda-Agrippino and Rey (2020) or Delle Chiaie et al. (2021). This model is able to extract latent factors capturing both (i) the global comovement and (ii) the group-specific comovements in the realized variance of agricultural, metals, and energy

\footnotetext{
${ }^{2}$ Some countries start a bit later: Argentina in 1993q2, Brazil in 1991q1, Colombia in 1996q2, Romania in 1995q1 and Turkey in 1998Q2.
} 
commodity futures returns.

Our dataset consists in a panel of commodity realized volatility series, $R V_{i, t}$, for $i=$ $1 \ldots, n$. We assume that demeaned realized volatility series can be described by the following group-specific dynamic factor model:

$$
R V_{i, t}=\beta_{i}^{G} F_{t}^{G}+\beta_{i}^{g} F_{t}^{g}+\varepsilon_{i, t}
$$

where $F_{t}^{G}$ is the global uncertainty factor and $F_{t}^{g}$ are the three group-factors $(g=1,2,3)$. Coefficients $\beta_{i}^{G}$ and $\beta_{i}^{g}, g=1,2,3$, are respectively the factor loadings measuring the impact of each commodity uncertainty $i$ on the global factor $F_{t}^{G}$ and the group-specific factor loadings measuring the impact of each commodity uncertainty $i$ on the group-factor $F_{t}^{g}$, for $g=1,2,3$. Finally, $\varepsilon_{i, t}$ is the error term and is assumed to be uncorrelated cross-sectionally at all leads and lags, but can be serially correlated. The error term is supposed to follow an $\operatorname{AR}(p)$ process such as:

$$
\varepsilon_{i, t}=\sum_{l=1}^{p} \psi_{i, l} \varepsilon_{i, t-l}+\epsilon_{i, t},
$$

where $\epsilon_{i, t} \sim \mathbf{N}\left(0, \sigma_{\epsilon}^{2}\right)$. The unobserved factors, $F_{t}^{G}$ and $F_{t}^{g}$, are also assumed to follow an $\operatorname{AR}(p)$ process of the following forms:

$$
F_{t}^{G}=\sum_{l=1}^{p} \psi_{l}^{G} F_{t-l}^{G}+\nu_{t}^{G}
$$

and for $g=1,2,3$ :

$$
F_{t}^{g}=\sum_{l=1}^{p} \psi_{l}^{g} F_{t-l}^{g}+\nu_{t}^{g}
$$

where $\nu_{t}^{G} \sim \mathbf{N}\left(0, \sigma_{G}^{2}\right)$ and $\nu_{t}^{g} \sim \mathbf{N}\left(0, \sigma_{g}^{2}\right)$. It turns out that both residuals in equation (3) and factors in equations (4)-(5) are characterized by short-term dynamics described by $p=3$. Finally, the innovations $\varepsilon_{i, t}, \nu_{t}^{G}$, and $\nu_{t}^{g}$, are mutually orthogonal across all equations within the system.

The model described by equations (2) to (5) is estimated through a Bayesian approach with Gibbs sampling, which is a Markov Chain Monte Carlo (MCMC) method for approximating 
joint and marginal distributions by sampling from conditional distributions. Using a MCMC procedure, we can generate random samples for the unknown parameters and the unobserved factors from the joint posterior distribution. This is feasible as the full set of conditional distributions is known, that is parameters given data and factors, and factors given data and parameters.

To describe our results, we employ variance decompositions measuring the relative contributions of the different factors to the variance of the realized variance for each individual commodity. Using previous notations, and assuming orthogonality between the various components, the variance of $R V_{i, t}$ is given by:

$$
V\left(R V_{i, t}\right)=\left(\beta_{i}^{G}\right)^{2} V\left(F_{t}^{G}\right)+\left(\beta_{i}^{g}\right)^{2} V\left(F_{t}^{g}\right)+V\left(\varepsilon_{i, t}\right)
$$

Finally, we can decompose the variance of each realized variance series, $R V_{i, t}$, into the fraction due to each of the two factors. In particular, the fraction of fluctuations due to any factor $f=G, g$ is given by:

$$
\frac{\left(\beta_{i}^{f}\right)^{2} V\left(F_{t}^{f}\right)}{V\left(R V_{i, t}\right)}
$$

Note that we obtain evaluations of equations (6) and (7) at each step of the Markov-Chain involved in the Bayesian estimation process.

\subsection{Assessing Impulse Response Functions through Structural VAR models}

Now that the common uncertainty factor has been estimated, we are interested in assessing its dynamic effects on some macroeconomic variables of our panel of countries. In particular, we will focus here on business investment and exports, while results for household consumption and GDP will be also considered in section 4. In this respect, we estimate a small-scale SVAR model in order to assess Impulse Response Functions (IRFs). Following Caggiano et al.(2014), we estimate for each country a 4-variable SVAR model in which we include our estimated commodity uncertainty factor, the inflation rate, a macroeconomic variable of 
interest (investment or exports) and the monetary policy rate (short-term interest rate of the country). The SVAR model that we estimate is given in Equation (8) below:

$$
A_{0} Y_{t}=c+A_{1} Y_{t-1}+\ldots+A_{p} Y_{t-p}+\varepsilon_{t}
$$

where $Y_{t}$ is the 4-dimension vector of endogenous variables, $c$ is a vector of constants, $A_{0}$ is the matrix of contemporaneous variables, $A_{1}$ to $A_{p}$ are matrices of coefficients controlling the autoregressive dynamics and $\varepsilon_{t}$ is a a vector of structural shocks serially uncorrelated, with zero mean and diagonal variance-covariance matrix $E\left(\varepsilon_{t} \varepsilon_{t}^{\prime}\right)=\sigma_{\varepsilon}^{2} I_{n}$. The lag-length $p$ for our SVAR models is selected using the Schwartz (SBIC) optimal-lag length information criterion ${ }^{3}$. The SBIC criterion selects a SVAR dynamics with two or three lags for most of country-specific SVARs, hence, for sake of comparability with factor dynamics we include three lags $(p=3)$ in all country-specific SVAR models for advanced and emerging economies. We estimate SVAR models for all advanced and emerging countries using the following ordering ${ }^{4}$ :

$$
Y_{t}=\left(u n_{t}, \pi_{t}, x_{t}, i_{t}\right)^{\prime}
$$

where $u n_{t}$ is the global commodity uncertainty as estimated by the common commodity uncertainty factor, $\pi_{t}$ is the quarterly inflation rate, $x_{t}$ is a given macroeconomic variable of interest (here, investment or exports) and $i_{t}$ is the nominal policy interest rate.

As usual in the econometrics literature, identification of the $A_{0}$ matrix is carried out by imposing some restrictions. In fact, our identification strategy relies on the exogenous uncertainty shocks approach as put forward by Bloom (2009). The main idea is to not include the commodity uncertainty factor into the SVAR model, but rather to directly include the estimated commodity uncertainty shock. In this respect, the commodity uncertainty shock is computed using the series of events collected by Piffer and Podstawski (2018), who include all

\footnotetext{
${ }^{3}$ Our SVAR estimates remain robust to the choice of lags to be included for the VAR model. More specifically, our SVAR results remain unaltered when using Akaike or Hannan-Quinn information criteria for optimal lag-selection of the SVAR models. Moreover, following Jo (2014) and Elder and Serletis (2010), we estimate our SVAR models using a full year of lags (4 quarters) and our main findings remain unaltered. These additional SVAR results are available upon request.

${ }^{4}$ Note that, for Argentina, in the absence of long series for inflation (quarterly Argentina inflation data available only for 2015 onwards), we estimate a 3-variable VAR model.
} 
the uncertainty episodes suggested by Bloom (2009) (peaks in the VXO index), as well as some recent additional events. Moreover, in order to account for the magnitude of the exogenously determined global commodity uncertainty shocks (unlike Bloom, 2009, who assigns the value of 1 to uncertainty events and zero otherwise), we define our uncertainty shock as follows:

$$
u n_{t}=F_{t}^{C} \times \mathbf{1}_{t}(\text { event })
$$

where $\mathbf{1}_{t}$ (event) is the indicator function that takes the value of 1 if an uncertainty event occurs at date $t$ and 0 otherwise. This definition of a shock has been adopted for example by Carrière-Swallow and Cespedes (2013) or Piffer and Podstawski (2018). Hence, the proxy for global commodity uncertainty takes the value of our original uncertainty factor series when, for a given quarter, a global uncertainty event takes place, and zero otherwise. In this way, we examine, not only the timing of uncertainty shocks, but also the magnitude of the exogenously determined commodity uncertainty shocks. This shock measure defined by Equation (10) is integrated as the first endogenous variable in our SVAR model given by Equation (8). Note that an alternative could be to introduce this shock as an exogenous variable in the SVAR model, as in Carrière-Swallow and Cespedes (2013) who use a small open economy assumption for each emerging country and treat shocks to S\&P500 price level and VXO index as exogenous to the local economies. As we deal with both advanced and emerging economies, we prefer to keep this variable endogenous into the model, as we assume dynamic feedback effects from macroeconomic changes to commodity uncertainty ${ }^{5}$. Using this specific ordering of variables and identification approach, we then estimate orthogonalized $\mathrm{IRFs}^{6}$. Since we include 12 emerging and 12 developing countries in our analysis, we estimate a total of 24 reduced-form SVARs as described by Equation (8). Aggregated IRFs for emerging and advanced countries as a whole are computed by taking the median of all the 12 IRFs for each group of countries. Lastly, in order to compare the dynamic effect of our commodity uncertainty shock with

\footnotetext{
${ }^{5}$ As robustness checks, we also estimate the SVAR model using the small open economy assumption as in Carrière-Swallow and Cespedes (2013), treating uncertainty shocks as strictly exogenous to local macroeconomic nominal and real outcomes, and our findings remain overall unchanged. Those results are available upon request.

${ }^{6}$ Robustness checks as regards model specification and identification are discussed in sub-section 4.2.
} 
Table 2: Factor loadings for the commodity price uncertainty series from the estimation of the commodity-specific DFM

\begin{tabular}{|l|cccc|}
\hline & $\beta^{G}$ & $\beta^{g=1}$ & $\beta^{g=2}$ & $\beta^{g=3}$ \\
\hline Corn & 0.87 & 0.69 & & \\
Cotton & 0.62 & 0.36 & & \\
Soybeans & 0.58 & 0.67 & & \\
Wheat & 0.57 & 0.56 & & \\
Copper & 1.15 & & 0.68 & \\
Gold & 0.41 & & 0.38 & \\
Silver & 1.43 & & 1.07 & \\
Platinum & 0.60 & & 0.38 & \\
Heating oil & 1.72 & & & 5.17 \\
Gasoline & 2.41 & & & 5.15 \\
Petroleum & 2.31 & & & 5.65 \\
Crude oil & 2.91 & & & 7.07 \\
\hline
\end{tabular}

responses to standard uncertainty shocks, we estimate similar SVARs using the VIX index, as a proxy for financial uncertainty, and the global Economic Policy Uncertainty index (EPU) of Baker et al. (2016), as a proxy for policy uncertainty measures. Empirical results are presented and discussed in Section 3 below.

\section{Empirical results}

\subsection{DFM estimation results}

First, let's consider estimation results from the Bayesian approach. Table 2 presents the estimated factor loadings for both global factor and the three-specific commodity sectors. We first note that all the loadings to the global factor, $\beta^{G}$, are positive, meaning that all commodities correlate positively with the global commodity uncertainty factor. Moreover, both loadings $\beta^{G}$ and $\beta^{g}$ are relatively similar for agricultural and metals volatilities, while $\beta^{g}$ appear to be much bigger than $\beta^{G}$ in the energy sector, reflecting thus a stronger correlation of volatilities with their respective commodity group-specific factor. This reflects the previously observed high correlation coefficients within the energy sector volatility variables (between $91 \%$ and $99 \%)$. 
Figure 1: Global commodity uncertainty factor

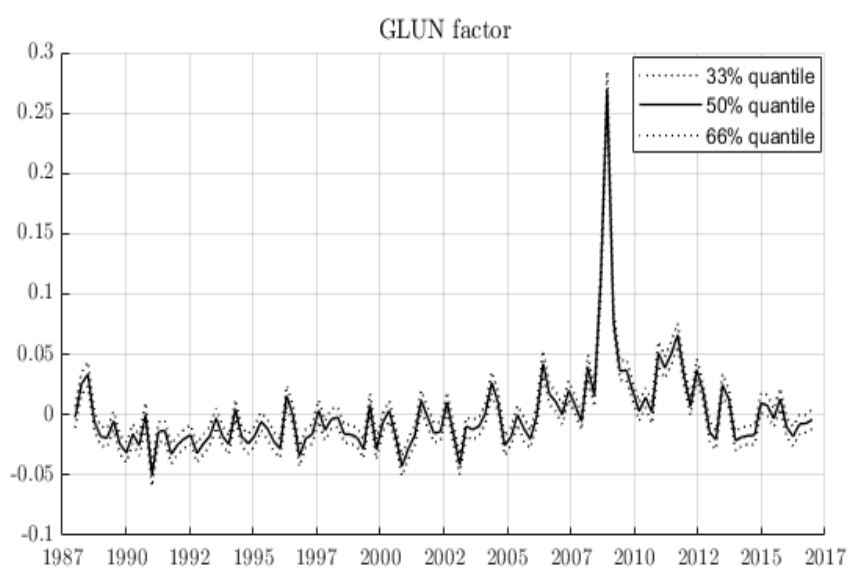

Note: This plot shows the time series of the global commodity uncertainty factor, which is the first factor of the Dynamic Factor model presented in Equations (2) to (7) and captures the comovement in the Realized Variance of agricultural, metals and energy commodity markets

Figure 1 shows the time series of the global commodity uncertainty (GLUN hereafter) factor, with confidence bounds. The tightness of the confidence bands demonstrates that the factor is precisely estimated. The GLUN factor appears to be quite low during the 1990s, then starts to slightly increase since 2000 to reach a peak during the Global Financial Crisis (GFC). The GFC was really an event that led to synchronized volatilities across all the markets. In the wake of the GFC, the commodity volatility stays high for a while, compared to previous levels, before coming back to lower levels.

Figure 2 shows the time series of the three commodity-specific factors, namely agricultural, metals and energy volatilities. Those three group-specific factors reflect the common uncertainty of each group deflated from the volatility common to all commodities, that is the GLUN factor. This is why, for example, we do not see any spike during the GFC, as this spike is common to all commodities and has been accounted in the GLUN. As regards the energy market, it seems to be the case that, as expected, the two oil shocks of the 1990's and in 2014 have widely affected the market, which displays peaks in the energy factor.

Variance decomposition results given by Equation (6) are presented in Table 3. Overall, we observe from this table that the idiosyncratic component is the least important driver for 
Figure 2: Commodity-specific uncertainty factors

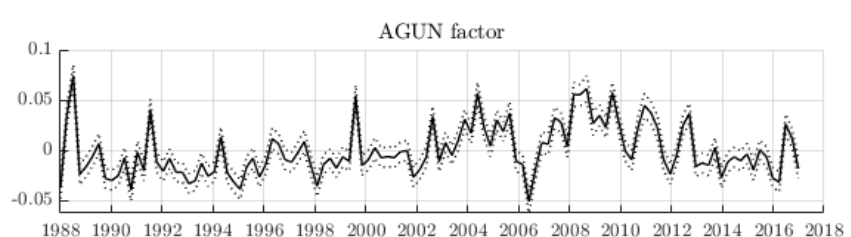

MTUN factor
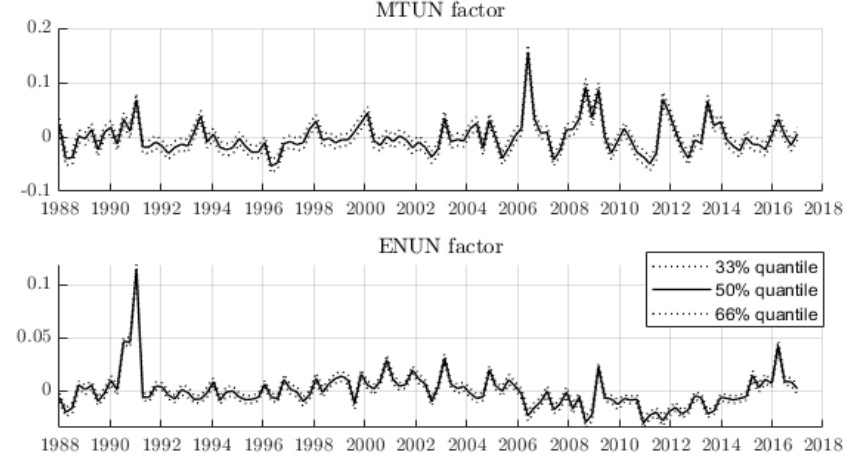

Note: This plot shows the time series of the commodity-specific uncertainty factors estimated from the Dynamic Factor model presented in Equations (2) to (7), for agricultural, metals and energy commodity markets.

most of the commodity volatilities, suggesting an important role for common factors, both global and group-specific, in explaining fluctuations in commodity price uncertainty. We also note that for agriculture and metals volatilities, the common commodity factor provides the largest contribution, meaning that the GLUN factor explains a large part of the variance for those variables. However, this is not the case for the energy market, for which market-specific factors explain nearly all the variability in the realized variance of those commodities. This reflects the fact that the correlations within volatilities of the energy sector are very strong.

\subsection{Macroeconomic responses to a global commodity uncertainty shock}

\subsubsection{Impact of the Global Uncertainty (GLUN) on investment}

Following the findings of the relevant literature of investment under uncertainty (Bernanke, 1983; Bloom, 2009), according to which rising uncertainty leads to postponement of investment, we first empirically examine to what extent our estimated GLUN factor has an impact 
Table 3: Variance decomposition from the estimation of the commodity specific DFM (in \%)

\begin{tabular}{|l|c|c|c|}
\hline & Global commodity factor & Commodity-group factor & Idiosyncratic component \\
\hline Corn & 62.5 & 23.2 & 14.1 \\
Cotton & 39.9 & 10.6 & 48.9 \\
Soybeans & 37.1 & 33.6 & 29.2 \\
Wheat & 40.9 & 20.5 & 38.1 \\
\hline Copper & 41.9 & 13.4 & 44.3 \\
Gold & 41.4 & 40.5 & 17.9 \\
Silver & 50.4 & 28.4 & 20.8 \\
Platinum & 40.2 & 17.4 & 42.1 \\
\hline Heating oil & 3.1 & 91.1 & 5.6 \\
Gasoline & 19.3 & 71.2 & 9.5 \\
Petroleum & 11.9 & 87.6 & 0.5 \\
Crude oil & 11.8 & 86.1 & 2.1 \\
\hline
\end{tabular}

on investment growth (INV). As previously described in Section 2, we base our analysis on the IRFs to the GLUN factor shock on investment growth of advanced and emerging countries, stemming from the baseline quadrivariate SVAR model presented in Equation (8).

IRFs to a global uncertainty shock are computed for all the countries in the sample and we take the median IRFs for the block of advanced economies and for the block of emerging market economies. Figure 3 plots the median IRFs, as well as their confidence intervals, for advanced and emerging countries (respectively first row of the left and right panels). Results show that the global commodity uncertainty shock leads on average to stronger and more persistent negative effects in emerging economies. The trough at $2 \%$ is reached after 3 quarters for emerging countries, while the trough is only of about $1.5 \%$ after 2 quarters for advanced economies. Notably, there is on average no visible bounce-back after the initial drop for both advanced and emerging countries. Those first results point out the common recessionary effect of a GLUN shock to major economies worldwide. Moreover, it is noteworthy that the GLUN shock leads to an adverse effect on investment irrespectively of whether the countries are net importers (mostly advanced countries) or net exporters (mostly emerging countries) of commodities ${ }^{7}$. Figure 11 in the Annex presents detailed results by country. It is striking to

\footnotetext{
${ }^{7}$ In both our set of developing and advanced economies, we include countries which are net importers of commodities, like Italy and Spain and countries which are producers and exporters of major oil and agricultural commodities like France, Norway and India
} 
Figure 3: Investment (INV) responses to exogenous GLUN, VIX and EPU shocks

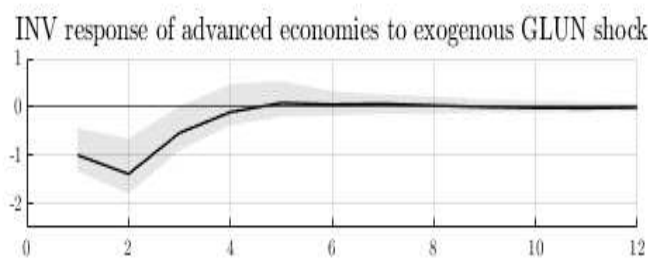

INV response of advanced economies to exogenous VIX shock

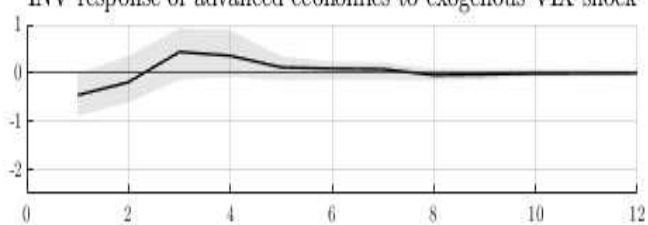

INV response of advanced economies to exogenous EPU shock

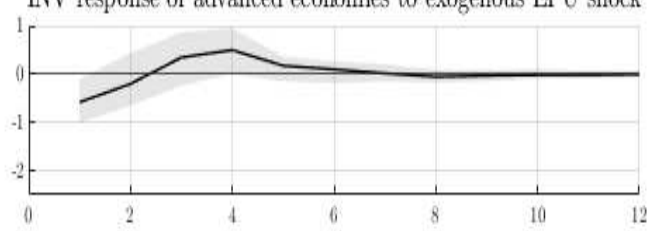

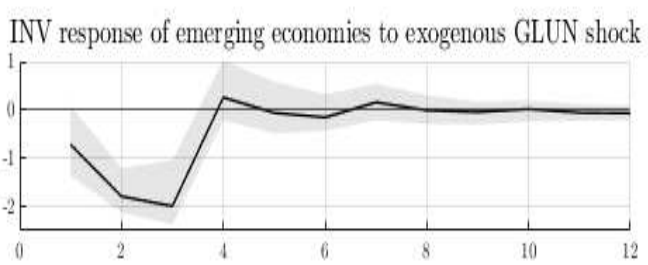

INV response of emerging economies to exogenous VIX shock

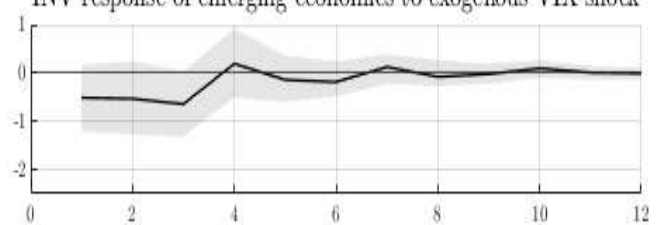

INV response of emerging economies to exogenous EPU shock

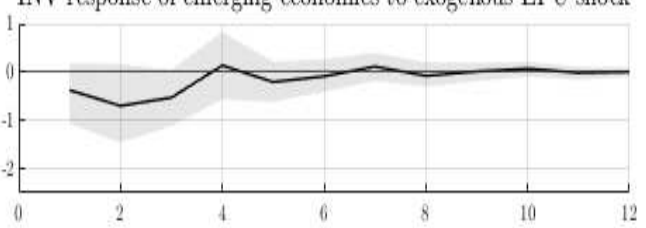

Note: The solid line shows the medians of the estimated IRFs (expressed in \%) for the set of advanced and emerging countries, while the shaded area shows the $68 \%$ bootstrapped confidence intervals using 1000 repetitions.

see that all the countries have been negatively impacted by a global commodity uncertainty shock. Some countries, in particular advanced countries such as Germany, Austria, Australia and Switzerland, tend to exhibit a bounce-back after the drop as initially put forward by Bloom (2009), but most of other countries do not present this specific over-shoot after the drop.

In order to compare the significance of the GLUN factor, we estimate our set of countryspecific quadrivariate SVAR models using alternative popular measures of uncertainty. In this respect, we focus on the VIX and the global Economic Policy Uncertainty (EPU) index, which are associated with business cycle fluctuations and economic recessions in the US and other major developed and emerging economies (see among others Bloom, 2009; Carrière-Swallow and Cespedes, 2013; Leduc and Liu, 2016; Baker et al., 2016). Median IRFs of investment, as well as confidence bounds, are presented in Figure 3 for both the VIX (middle graph of left and right panels) and the EPU (bottom graph of left and right panels). The response of investment in advanced countries to a GLUN shock is significantly higher in magnitude and 
persistence, compared with the respective responses of advanced countries to VIX and EPU shocks. More specifically, our estimated IRFs show that investment in advanced countries reaches a minimum of about $-0.5 \%$ and $-0.6 \%$ following VIX and EPU shocks, respectively, while it reaches $-1.5 \%$ two quarters after the initial GLUN shock. Moreover, we do not see evidence of a bounce-back after a GLUN shock, while IRFs from investment to VIX and EPU shocks come back into positive territory after four quarters. As regards emerging markets, we also find that a GLUN shock leads to a stronger negative response than VIX and EPU shocks, but none of the shocks is able to generate a bounce-back after the initial drop.

Interestingly, we confirm the results put forward by Carrière-Swallow and Cespedes (2013, Figure 3, p. 320), in the sense that we observe a bounce-back in investment few quarters after a VIX shock in advanced economies (also in line with seminal Bloom's paper, 2009), but not in emerging economies. The authors attribute this differential between the two types of economies to the presence of financial frictions during high uncertainty periods in emerging countries. That is, when an uncertainty shock hits, it becomes much more difficult for companies located in emerging countries to get access to credit to fund their projects, as the financial sector is less developed. This result means that financial uncertainty shocks are likely to have permanent effects on the level of investment in emerging countries, and thus on potential growth through the accumulation of capital. On the contrary, this effect appears to be more temporary in advanced countries. As a new result, we show here that an EPU shock also leads to similar contrasting results between advanced and emerging countries. Indeed, we get a strong bounce-back few quarters after an EPU shock on investment in advanced countries, while there is no evidence of such pattern in emerging economies. This also means that EPU shocks in emerging economies possess persistent effects on the level of investment, and thus on potential growth. Wrong economic policies that generate uncertainty are thus extremely damaging for long-run economic growth in emerging economies. In opposition, this differentiation between the two types of countries doesn't hold after a GLUN shock, as both advanced and emerging countries do not exhibit any recovery after the initial drop in investment. This latter result suggests that global commodity shocks can be detrimental for the long-run growth of the global economy as it is permanently affecting the investment level 
Figure 4: Exports' responses to exogenous GLUN, VIX and EPU shocks

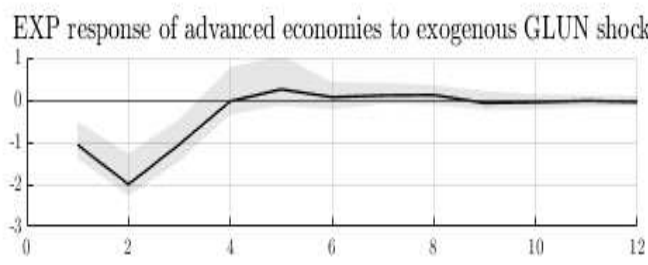

EXP response of advanced economies to exogenous VIX shock

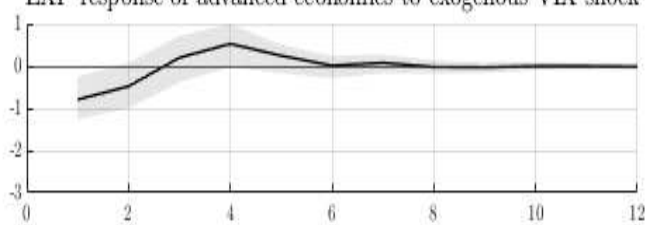

EXP response of advanced economies to exogenous EPU shock

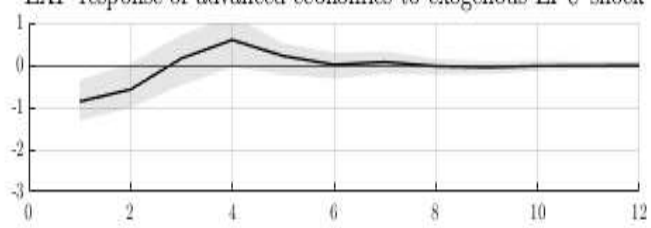

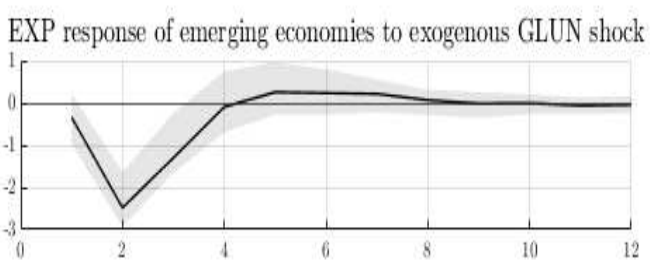

EXP response of emerging economies to exogenous VIX shock

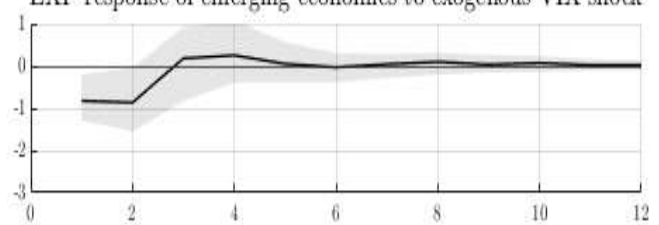

EXP response of emerging economies to exogenous EPU shock

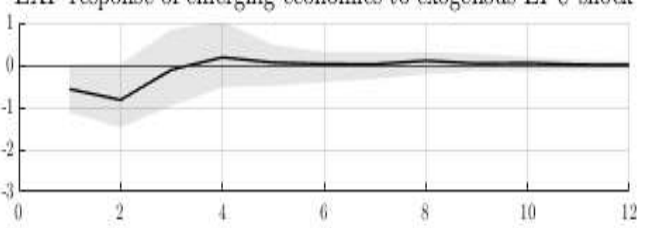

Note: The solid line shows the medians of the estimated IRFs (expressed in \%) for the set of advanced and emerging countries, while the shaded area shows the $68 \%$ bootstrapped confidence intervals using 1000 repetitions.

in both advanced and emerging countries. Overall, our benchmarking analysis clearly shows that the GLUN factor leads to larger drops in investment in both advanced and emerging economies when compared to the respective impact of popular uncertainty proxies like the VIX and EPU indexes.

\subsubsection{Impact of the Global Uncertainty (GLUN) on exports}

We now focus on the response of exports to various types of uncertainty shocks. To do that, we replace the third variable in the SVAR (investment) with the quarterly exports growth (EXP) and carry out the same SVAR analysis as previously shown. Figure 4 shows the aggregate response of advanced and emerging countries, compared to VIX and EPU shocks ${ }^{8}$. SVAR results clearly highlight the persistently negative response of exports of advanced and emerging economies to a GLUN shock. More specifically, both advanced and emerging countries exports growth decreases by approximately $2 \%$ and $2.5 \%$, respectively, after a positive GLUN shock,

\footnotetext{
${ }^{8}$ Detailed results by country are presented in Figure 12 in the Annex
} 
with the effect remaining negative and statistically significant for two quarters after the initial uncertainty shock. Similarly, both VIX and EPU shocks (middle and bottom graphs of left and right panels, respectively) have a negative impact in the very short-run on exports of both advanced and emerging countries. Interestingly, we also observe a differentiated impact between advanced and emerging countries, in the sense that a bounce-back after the initial drop in exports growth is only visible in advanced countries. A possible explanation relies on financial frictions that limit the ability of exporters to borrow when global commodity uncertainty jumps. When comparing the GLUN shock with VIX and EPU shocks, Figure 4 shows that the dynamic negative effect of a GLUN shock to exports is significantly larger compared to that of VIX and EPU shocks. This result confirms those for investment, meaning that a GLUN shock leads to a sharp reduction in the growth rate of economic variables. Moreover, in advanced economies, the recovery in exports reaches its peak one year after the initial VIX and EPU shock, while it needs five quarters for it to be reached after a GLUN shock. Note also that the amplitude of the recovery is lower after a GLUN shock. This means that a GLUN shock has a more persistent long-run impact on the level of exports of advanced economies than the VIX and EPU shocks. As regards emerging economies, the amplitude of recoveries after all types of shocks is similar, and non-significant, though the recovery is lagged after a GLUN shock.

\subsection{Macroeconomic responses to commodity-specific uncertainty shocks}

In this subsection, we empirically assess the dynamic macroeconomic effects of the commodityspecific uncertainty factors, once the global uncertainty has been removed. The three commodityspecific factors, i.e. the agricultural price uncertainty (AGUN), the energy price uncertainty (ENUN) and the metals' price uncertainty (MTUN) factors, are presented in Figure 2. Given that these group-specific factors capture uncertainty comovement within each group, a surge in uncertainty within those sectors is likely to happen when there are some specific news related to those markets, for example related to climatic conditions as regards agricultural commodities, or related to OPEC news as regards energy commodities. 
Figure 5: Investment responses to exogenous AGUN, ENUN, and MTUN shocks.

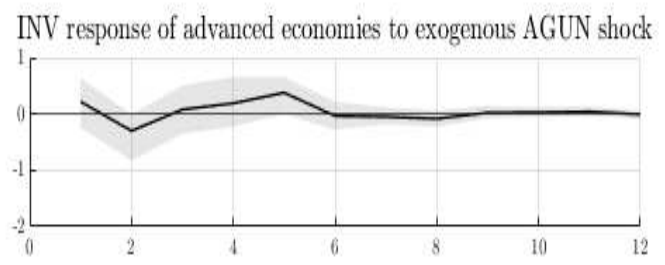

Wriv

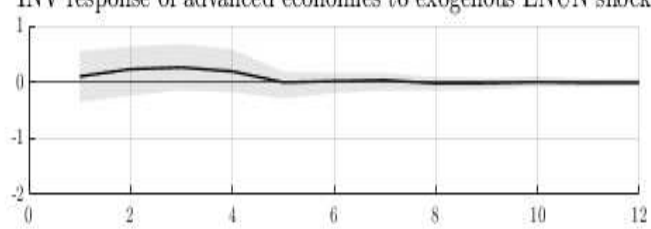

INV response of advanced economies to exogenous MTUN shock

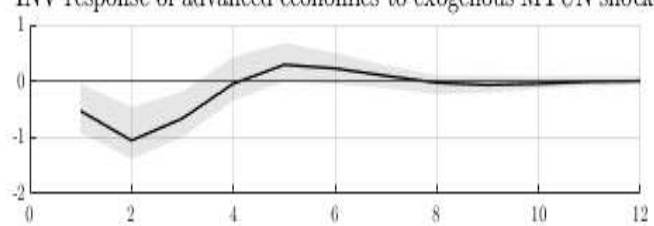

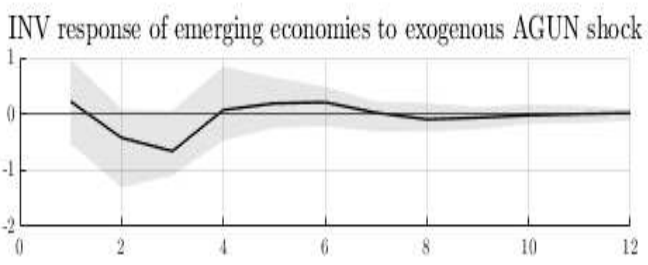

INV response of emerging economies to exogenous ENUN shock

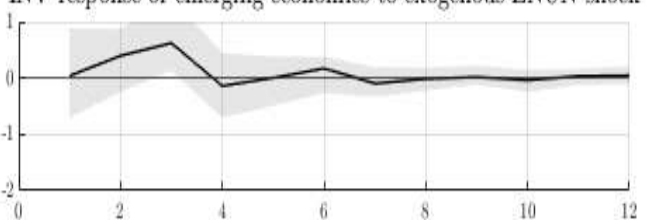

INV response of emerging economies to exogenous MTUN shock

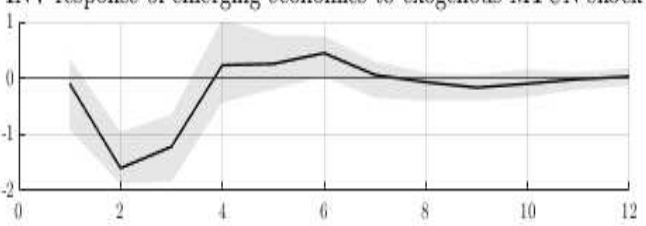

Note: The solid line shows the estimated IRFs (expressed in \%), while the shaded area shows the 68\% bootstrapped confidence intervals using 1000 repetitions.

\subsubsection{Impact of commodity-specific uncertainties on investment}

Let's first consider the impact of commodity-specific uncertainty shock on aggregate investment. In this respect, we estimate for all countries the baseline quadrivariate SVAR model given by Equation (8) using alternatively the AGUN, MTUN and ENUN shocks as the first variable in the ordering. Figure 5 presents the results obtained at the aggregate levels, for both advanced (left panel) and emerging economies (right panel), as regards estimated IRFs from INV to AGUN, MTUN and ENUN shocks, respectively. Detailed results for all countries can be found in Figures 13, 14 and 15 in the Annex.

Focusing first on advanced economies, we can see in the left panel of Figure 5 that only a shock on metals uncertainty is able to generate a significant negative response from investment, as well as a bounce-back after few quarters. This is the typical shape of an uncertainty shock on investment as put forward by Bloom (2009). This reflects the fact that metal prices are strongly related to investment growth, so higher uncertainty concerning future metal prices is likely to activate the real-option channel and a wait-and-see strategy from companies. This result reinforces the idea that prices in the metal sector are strongly associated 
with the global business cycle (Fama and French, 1988; Labys et al., 1999; Hamilton, 2014; Huang and Kilic, 2019). In opposition, IRFs resulting from agricultural- and energy-specific uncertainty shocks do not appear to be significant. As far as energy uncertainty is concerned, this result is surprising as the relevant literature has so far identified a significant negative response of global economic activity to oil price uncertainty shocks (Elder and Serletis, 2010; Jo, 2014; Elder, 2018). This result does not imply that energy uncertainty shocks are not important, but rather that shocks in energy uncertainty are important when they coincide with shocks in agriculture and metals. We discuss this puzzle in Section 4.

Focusing on emerging economies, we can see in the left panel that all the three shocks have larger effects on investment compared to advanced countries, though MTUN shock appears again to generate a much stronger response. But, both IRFs to AGUN and ENUN shocks appear to be slightly significant after three quarters. Interestingly, our SVAR analysis shows for the first time in the empirical literature, at least to our knowledge, that the investment response of many emerging countries, such as Brazil, Indonesia, South Africa and Turkey, to an energy uncertainty shock turns out to be positive (see Figure 14 in the Annex). That's also true for some advanced countries such as Austria, Canada, France, Germany or Italy. In theory, such results are plausible, but are rarely put forward in practice. Indeed, Bloom (2014) recalls that an uncertainty shock can potentially have a positive impact on growth through the growth-option channel. This channel occurs when potential positive outcomes largely outweigh potential negative outcomes. We can imagine that this is especially the case for energy prices that are able to reach very high levels, sometimes extremely rapidly. Such a situation is also likely to happen when the costs of bad outcomes have a limited lower bound. Punzi (2019) put also forward another possible channel of transmission via an immediate higher consumption of energy by both households and companies. We discuss this issue in the next section.

\subsubsection{Impact of commodity-specific uncertainties on exports}

We replicate the previous analysis by replacing the variable INV by EXP in the SVAR model given by Equation (8) and by using sequentially AGUN, MTUN and ENUN shocks. Figure 
Figure 6: Exports' responses to exogenous AGUN, ENUN, and MTUN shocks.

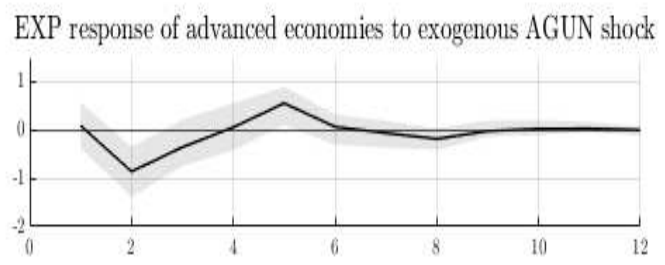

EXP response of advanced economies to exogenous ENUN shock

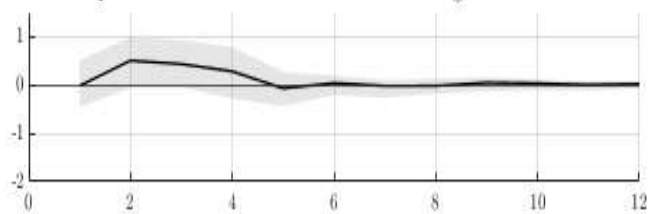

EXP response of advanced economies to exogenous MTUN shock

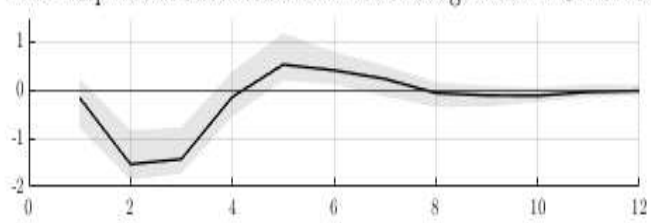

EXP response of emerging economies to exogenous AGUN shock

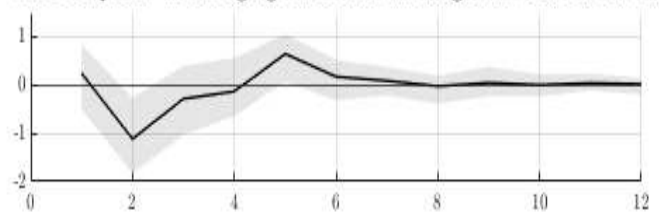

EXP response of emerging economies to exogenous ENUN shock

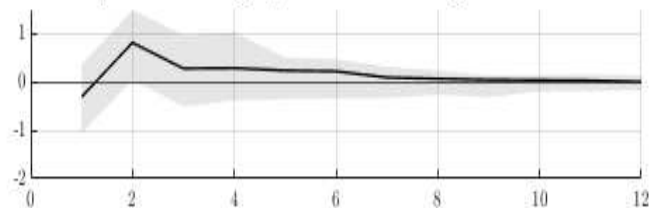

EXP response of emerging economies to exogenous MTUN shock

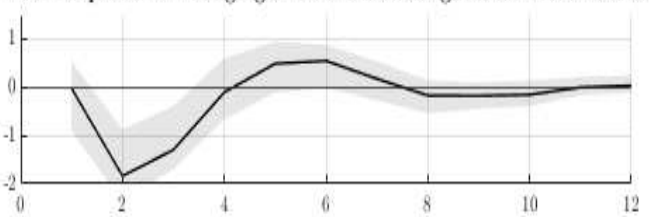

Note: The solid line shows the estimated IRFs (expressed in \%), while the shaded area shows the 68\% bootstrapped confidence intervals using 1000 repetitions.

6 presents the results obtained at the aggregate levels, for both advanced (left panel) and emerging economies (right panel), as regards estimated IRFs from exports to AGUN, MTUN and ENUN shocks, respectively ${ }^{9}$.

It is striking to see that MTUN and AGUN shocks generate a significant negative shortrun drop on exports, followed by a recovery that peaks five quarters after the shock. Those results hold for both advanced and emerging countries. We note that uncertainty on metals prices tend to lead to a more significant and persistent negative impact on exports than uncertainty on agricultural prices. Similarly, to what we observed for investment, exports also tend to react positively to an ENUN shock, though this effect is found to be significant only for the second quarter after impact.

\subsection{Robustness checks}

We have carried out various robustness checks in order to validate our empirical results.

\footnotetext{
${ }^{9}$ Detailed results for all countries can be found in the online appendix.
} 
First, in addition to investment and exports, we also consider two major macroeconomic variables, namely Gross Domestic Product (GDP) and private consumption expenditures (CONS). IRFs to a GLUN shock stemming from SVAR models estimated alternatively using GDP and consumption are presented in Figure 7, for both advanced (left panel) and emerging economies (right panel) ${ }^{10}$. We also plot on the same graph IRFs from investment and exports, so that results can be directly comparable. Overall, we find that a GLUN shock has roughly the same dynamic effect on those measures of economic activity, though aggregate GDP appears to be somewhat less affected. In this way, we show that our results and conclusions as regards the dampening effect of GLUN shock on economic activity are robust to the choice of the economic activity variable. From Figure 7 we also see that exports are more severely impacted from GLUN shocks compared to investment and consumption.

Figure 7: Macroeconomic responses to various energy uncertainty shocks
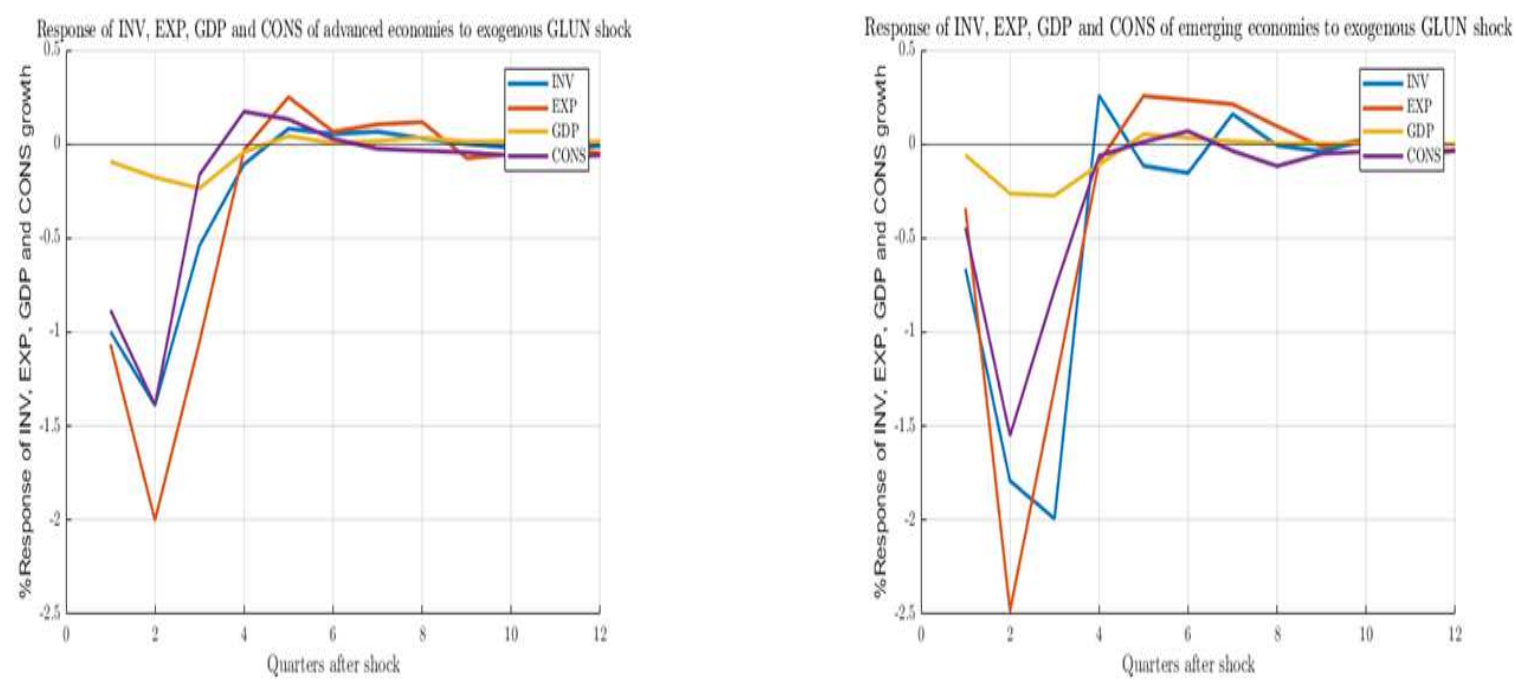

Second, it might be the case that first moments and second moments of commodity prices could be related. For example, we can imagine that during large drops in oil prices, as the ones we observe at the heart of the Covid crisis or mid-2014, uncertainty tends to increase. To account for this, we estimate a small-scale 5-variable SVAR by adding changes in commodity prices to the model given by equation (9). We assume exogeneity of commodity prices, as proxied by the GSCI commodity index, and we rank changes in this index in first position

\footnotetext{
${ }^{10}$ The results on the effects of GLUN, AGUN, MTUN and ENUN shocks on real GDP and consumption expenditures of advanced and emerging countries can be found in the online appendix.
} 
within the SVAR model, as done for example by Bloom (2009). IRFs for investment and exports are then computed to assess the response to a commodity price uncertainty shock. We get that results are extremely similar to those presented in the previous subsection $3.2^{11}$, meaning that our results are robust to the presence of commodity prices. Interestingly, we also get that investment and exports are stimulated by an exogeneous shock on the level of commodity prices, in line with existing literature (Delle Chiaie et al., 2021).

As additional robustness checks, we show that our SVAR model does not appear to be sensitive to the choice of lags included and to the ordering of the variables. We also include various other proxies for economic uncertainty like the geopolitical uncertainty index of Caldara and Iacoviello (2018) and other well-known measures of oil price and uncertainty shocks (Kilian, 2009; Elder and Serletis, 2010) and we show that the dynamic effect of the GLUN factor is more significant when compared with that of oil price and uncertainty shocks. We also estimate a 3-factor SVAR model in which we shut-down the policy rate and our results remain unaltered. Finally, we estimate our SVAR model in which we treat commodity uncertainty shocks as endogenous to the local economies and our results remain unchanged. All those results are available upon request.

Last, we check the robustness of our results to an alternative identification scheme in the SVAR model. While in our analysis we identify the GLUN shocks during the events linked to global macroeconomic uncertainty (as in Bloom, 2009 or Piffer and Podstawski, 2018), here we identify commodity price uncertainty shocks in a "commodity world". By the term "commodity world" we mean that we identify shocks as the spikes in the GLUN index, using the approach put forward by Bloom (2009) on the VIX index. That is we identify the shocks as the spikes (i.e. GLUN observations which are 1.65 standard deviations above the mean) in the detrended GLUN series. Strikingly, we get that our main findings on the recessionary effect of GLUN shocks remain unaltered when moving to a "commodity world", reinforcing thus our empirical results ${ }^{12}$.

\footnotetext{
${ }^{11}$ Results related to the IRFs are available upon request

${ }^{12}$ Results are available upon request
} 


\section{Disentangling "good" and "bad" outcomes from an oil price uncertainty shock}

The literature on uncertainty in commodity prices usually focuses on energy commodities, and in particular on oil prices. Overall, empirical results tend to show that an oil price uncertainty shock leads to negative effects on economic activity, as shown for example by Elder and Serletis (2010) or Jo (2014). However, some recent papers are also showing the opposite, that is that oil price uncertainty could generate positive macroeconomic outcomes, in line with the growth-option theory as put forward by Bloom (2014). For example, empirical evidence of a positive relationship between oil uncertainty and economic activity has been provided by Mohn and Misund (2009) using micro data on oil companies. They show that industryspecific uncertainty can have a stimulating effect on oil investment and output. Looking at the copper mining industry in the U.S., Marmer and Slade (2018) point out that greater uncertainty encourages investment and lowers the price thresholds for many mines. Their argument is that when projects are large and take time to build, then there exists a given level of uncertainty over which investment is stimulated. From a theoretical point of view, Punzi (2019) develops a small open economy Dynamic Stochastic General Equilibrium model in which oil price uncertainty shocks generate short-term positive growth on GDP, consumption and investment. Those results are confirmed by an empirical analysis on some Asian countries using a Panel VAR model. The main underlying idea is that, facing possible jumps in oil prices in the future, households and companies decide to increase their consumption of energy at the present moment.

In fact, uncertainty can be split into "good" and "bad" uncertainty, the overall aggregate effect depending on the weight of each component. Using the Bloom's (2014) terminology, the "bad" uncertainty activates the real-option channel and/or the risk-premium channel, leading to adverse macroeconomic effects, while the "good" uncertainty activates the growth-option channel, leading thus to positive macroeconomic outcomes. For example, when defining an uncertainty shock as an increase in the second moments of the distribution of future events, Forni, Gambetti and Sala (2021) propose to decompose total uncertainty between "downside 
uncertainty", the part originating from the left tail of the distribution, and "upward uncertainty", the part originating from the right tail. Using a combination of quantile regressions and SVAR models, they empirically show on U.S. data that uncertainty shocks are not necessarily recessionary and that the overall sign of the macroeconomic impact depends on the source of the uncertainty shock ("downward" vs "upward") and the contributions of each component. Segal et al. (2015) get similar results by disentangling the "good" and "bad" uncertainty effects on aggregate output and asset prices using positive and negative realized semi-variances.

In this section, we come back on the results presented in the previous section 3 in which we pointed out how our approach can be seen as an efficient way to decompose between "good" and "bad" oil price uncertainty shocks. To understand the intuition behind our results, we estimate two other models in addition to the group-specific DFM given by Equation (2). First, we estimate a standard DFM in a Bayesian framework, using only the four energy uncertainty measures that relate to the oil market, namely crude oil, heating oil, gasoline and petroleum. We assume there is only one factor that captures the common comovement across those four energy uncertainty measures, namely the pure energy uncertainty factor. Table 1 highlights the very high correlation between the uncertainty measures of those four energy commodities (correlation coefficients ranging from 91\% to 99\%). We then integrate this pure energy uncertainty factor into a SVAR model, as described in section 3.3 in order to assess its effects on investment. The bottom graph in Figure 8 ('1-factor ENUN' shock) shows that an increase in pure energy uncertainty is associated with a negative response from investment ${ }^{13}$. This result holds for both advanced and emerging economies. Take-away 1 of this comparison exercise: a pure energy uncertainty shock leads to a negative effect on economic activity, as usually highlighted in the literature.

Secondly, we re-estimate a standard DFM with only one common factor across the twelve commodities series. This model is given by Equation (2) with $\beta_{i}^{g}=0$, for all $g=1,2,3$. Table 1 also highlights a significant correlation between the volatility measures of all twelve commodities. Note also that if we estimate a standard DFM for the four metals' volatilities and

\footnotetext{
${ }^{13}$ Similar results hold for GDP, exports and consumption
} 
Figure 8: Investment responses to various energy uncertainty shocks

INV response of advanced economies to exogenous 1-factor GLUN shock

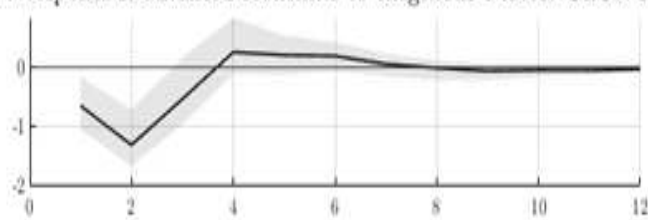

INV response of advanced economies to exogenous 2-factor GLUN shock

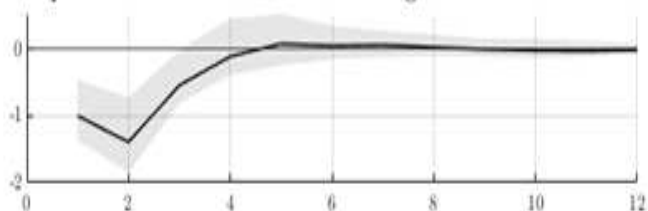

INV response of advanced economies to exogenous 1-factor ENUN shock

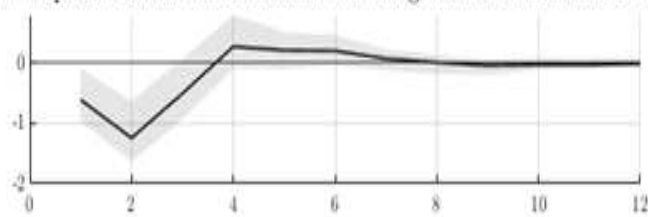

INV response of emerging economies to exogenous 1-factor GLUN shock

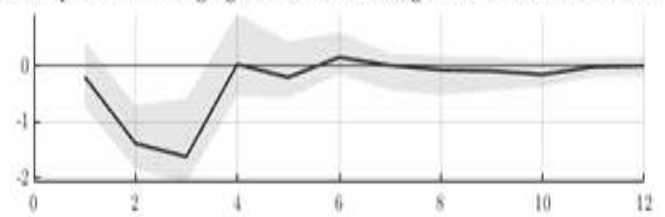

INV response of emerging economies to exogenous 2-factor GLUN shock

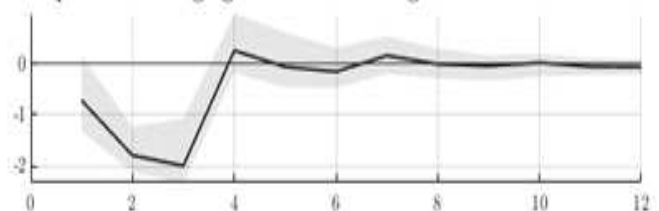

INV response of emerging economies to exogenous 1-factor ENUN shock

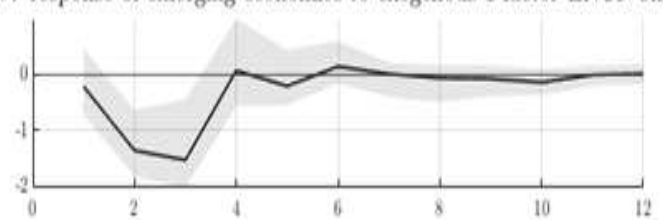

for the four agricultural volatilities, separately, we get that pure metals and pure agricultural factors possess a strong correlation with the pure energy factor ${ }^{14}$. This suggests evidence of a common pattern within commodity uncertainty measures. The estimation of this one factor DFM enables us to directly extract the comovement among those twelve volatility measures. When doing this exercise, the results show that the four energy commodity volatilities contribute to a very large extent to the common factor. Indeed, a variance decomposition analysis shows that the common factor explains between $90 \%$ and $99 \%$ of the variance of the four energy uncertainties. As a comparison, industrial commodities are close to $20 \%$ on average, while agricultural commodities represent about $8 \%$ on average. Take-away 2: including only one factor to get common dynamics across commodities of different markets might bias the results by magnifying the role of energy and downplaying the role of agriculture and metals in the construction of the common factor. This result is mainly driven by the extremely high correlation within the energy commodities as previously shown in Table 1 . The level of groupstructure used to capture the comovement is important as shown by Kose et al. (2003) and Karadimitropoulou and Leon-Ledesma (2013). Failure to use the appropriate group-structure

\footnotetext{
${ }^{14}$ Correlation is equal to 0.66 between pure uncertainty factors of agriculture and metals, to 0.30 between agriculture and energy and to 0.48 between energy and metals
} 
implies that the comovement in commodity uncertainties contained in this global one-factor model mainly reflects the comovement within the energy sector. The IRFs stemming from this one-factor DFM are presented in Figure 8 (top graph, referred to as "1-factor GLUN shock"). We observe that the response of investment to a "1-factor GLUN shock" is pretty much identical to the response of investment to a "1-factor ENUN shock" obtained using only the four energy variables. Moreover, the middle graph of Figure 8, namely "2-factor GLUN shock", represents the IRFs stemming from our estimated commodity-specific DFM, the two-factor model, whose results are described in section 3. We observe that the responses of investment to a GLUN shock are similar to the other two estimated DFMs. Take-away 3: an energy uncertainty shock will have recessionary effects on economic activity when this shock is common to agricultural and metals commodities.

Last, when looking at Figure 5 (for investment) and Figure 6 (for exports), we note that, once we account for global uncertainty, the remaining energy-specific price uncertainty shocks generate positive short-run outcomes on investment and exports, though the IRFs are only slightly significant on average for advanced and emerging economies ${ }^{15}$. Figure 14 in the Annex presents those results country by country for investment. We observe positive response to energy uncertainty shocks for many countries, mainly energy producers like Norway, Australia, UK or Mexico. Similar results hold for exports, consumption and GDP. Take-away 4: when decomposing energy uncertainty into two main components, that is the part of uncertainty that comoves with other non-energy commodities and the part of uncertainty that is specific to the energy market, the results suggest that those two components will have opposite effects on economic activity (i.e. investment, exports, consumption, and GDP). Thus we point out here innovative findings as regards the way to decompose between "good" and "bad" oil price uncertainty shocks through a group-specific DFM. Our approach constitutes an alternative way for this kind of decomposition, different from the ones from Segal et al. (2015) or Forni et al. (2021).

\footnotetext{
${ }^{15}$ Similar results hold for other macroeconomic aggregates, such as GDP and consumption. Detailed results are available in the online appendix)
} 
In order to compare our results on "good" and "bad" uncertainty shocks, let's try to assess positive and negative effects of a global uncertainty shock on investment in a more standard way. We assume that an uncertainty shock supposed to have a negative impact on the global economic activity as a whole is likely to be associated with an increase in commodity prices. Obviously such an increase in commodity prices is not necessarily negative for all actors, as for example net oil exporters, but there are good reasons to think that the overall impact on the global economy is supposed to be negative given the still strong dependence of production and consumption to energy. Conversely, a positive uncertainty shock is likely to be associated with a drop in energy prices. Thus a bad global uncertainty shock is equal to GLUN when commodity prices are in an upward phase and zero otherwise. We define a good uncertainty shock in a similar manner. Upward and downward phases of commodity prices are computed by identifying peaks and troughs in the commodity price cycles, using the Bry and Boschan (1971) algorithm applied to the quarterly GSCI index. This approach aims at identifying local maxima and minima in a given time series in a non-parametric way. Then, in a second step, we sequentially include both positive and negative global uncertainty shocks into our small-scale SVAR model. Results for IRFs are presented in Figure 9. We observe that the recessionary effect of GLUN shocks stems from the "bad" commodity uncertainty component. More specifically, in accordance with the relevant literature on the effects of "good" and "bad" uncertainty, the "bad" GLUN shock leads to persistent drop in investment and exports growth of advanced and emerging economies of approximately $2 \%$, with the recessionary effect remaining significant for three quarters after the "bad" GLUN shock. On the other hand, the macroeconomic impact of "good" GLUN shocks is non-significant for our set of advanced economies and rather transitory and negligible for emerging economies. These results are the first to show that the recessionary effect of the GLUN shock comes mainly through the "bad" component of GLUN series, which is associated with rising commodity prices. However, this standard approach does not allow to highlight the positive impact of uncertainty on global economic activity, while our approach provides deeper insights on this decomposition. Let's also note that similar results hold for "good" and "bad" oil uncertainty shocks, but with a lower amplitude. 
Figure 9: Investment responses to bad and good global uncertainty shocks

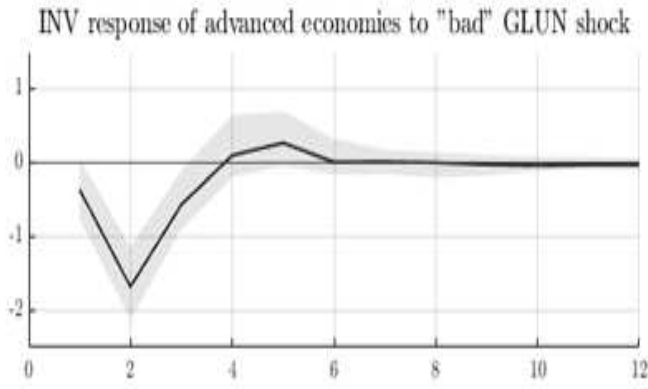

INV response of adranced economies to "good" GLUN shock

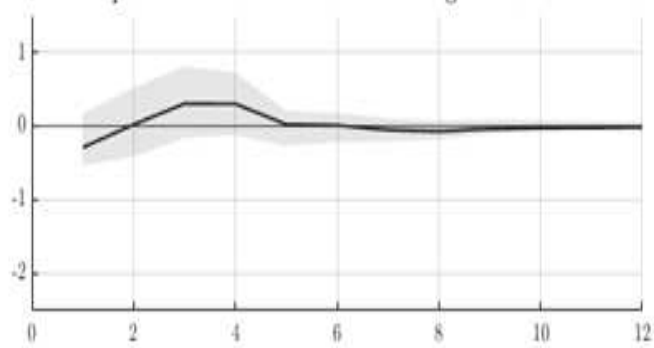

INV response of emerging economies to "bad" GLUN shock

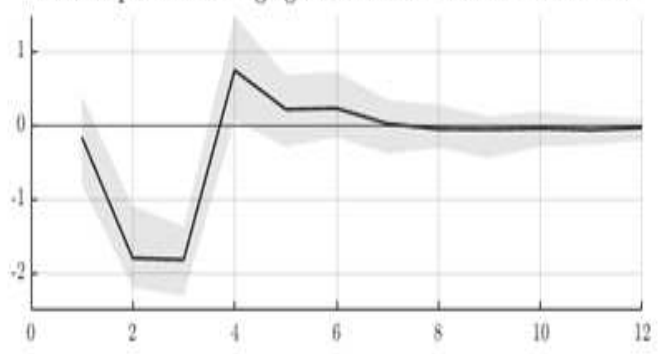

INV response of emerging economies to "good" GLUN shock

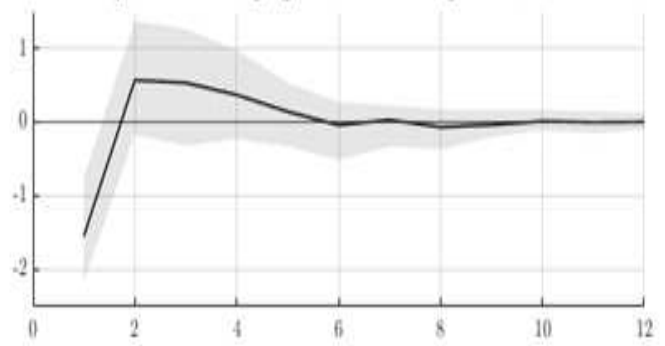

Overall, the lesson of this empirical analysis is the following: when trying to disentangle the "good" and "bad" macroeconomic effects of oil price uncertainty, considering other commodity prices seems to be crucial. It turns out that when the spike in uncertainty is common to all commodities, then the macroeconomic impact is likely to be negative, as one could expect. However, when the uncertainty increase is specific to the oil market, then the macroeconomic effect generally tends to be positive in the short run, as advocated for example by Punzi (2019). Our initial interpretation is that uncertainty shocks that simultaneously affect all commodities are likely to reflect global demand uncertainty, whereas commodityspecific price uncertainty shocks are more likely to stem from the supply side of some specific commodity markets. This would be in line with the analysis put forward by Delle Chiaie et al. (2021) when dealing with the level of commodity prices. To confirm this result, we employ a simple strategy consisting in comparing IRFs for prices and output. It is indeed widely acknowledged that when prices and output go in the same direction after a given shock, this likely reflects a demand shock, while when prices and output go in opposite directions, the shock is likely to come from the supply side. Looking at the top panel of Figure 
Figure 10: IRFs of inflation in advanced economies to global uncertainty shock and commodity-specific uncertainty shocks
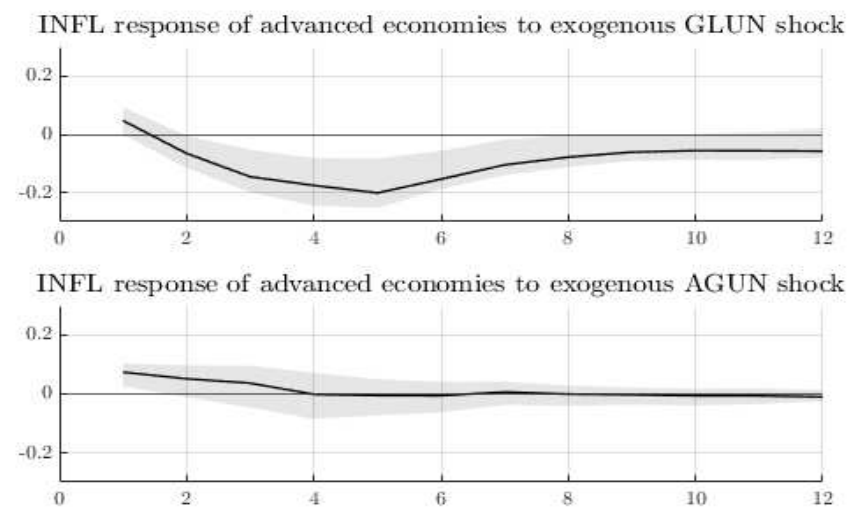

INFL response of advanced economies to exogenous ENUN shock

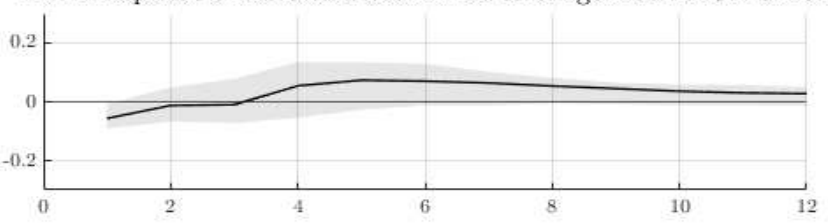

INFL response of advanced economies to exogenous MTUN shock

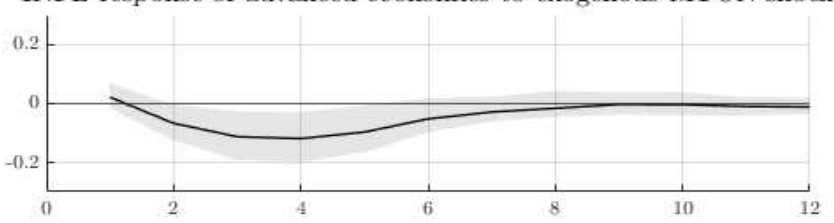

10, we note that for advanced economies ${ }^{16}$, a global uncertainty shock leads to deflationary pressures meaning that, associated with the negative impact on macro variables described in sub-section 3.2.1, this type of shock acts as a negative demand shock. This result is well in line with intuition. However, the three commodity-specific shocks (Figure 10) tend to lead to non-significant responses, meaning that those shocks cannot be considered as pure supply shocks but they very likely reflect a mix of shocks, including supply and market-specific demand shocks (using Kilian's, 2009, terminology).

${ }^{16}$ As far as emerging economies are concerned, IRFs are not found to be significant. 


\section{Conclusions}

The global economy is facing many uncertainties from various sources. In this paper, we shed light on one particular type of uncertainty, that is the uncertainty inherent to commodity prices, as proxied by their volatility. Generally, the literature tends to only focus on oil price uncertainty, pointing out its negative impact on economic activity (Elder and Serletis, 2010; Jo, 2014; Elder, 2018). Yet, our results highlight that this is not only an oil story and that looking at the common uncertainty across various commodities provides important and useful information.

By properly extracting the uncertainty component common to various commodity prices through a commodity-specific Dynamic Factor Model, we show that a global commodity uncertainty shock leads to a significant adverse impact on economic activity as measured by investment, exports, consumption or GDP, for both short and long horizons. We also show that this type of shock turns out to be more detrimental for economic activity than usual uncertainty shocks, such as financial uncertainty or economic policy uncertainty shocks.

Our methodology can be seen as a way to disentangle "good" and "bad" macroeconomic effects of oil price uncertainty. It turns out that when a rise in oil price uncertainty is common to all commodities, then the macroeconomic impact is likely to be negative, as generally put forward in the literature. By looking at both responses of inflation and real macroeconomic variables, we show that a global uncertainty shock can be interpreted as a global demand shock. However, when the uncertainty increase is specific to the oil market, that is when global uncertainty has been accounted for, then the macroeconomic effect tends to be positive in the short run, in line with existing literature on growth-option theory.

A policy recommendation which stems out of our analysis is that economic policies should also turn their attention to non-oil commodity price when they monitor global uncertainty measures, and not only to oil price volatility. 


\section{References}

[1] Ahir, H., N. Bloom, and D. Furceri (2019), The global economy hit by higher uncertainty, VoxEU.org.

[2] Alquist, R., Bhattarai, S., and Coibion, O. (2020). Commodity-price comovement and global economic activity. Journal of Monetary Economics, 112, 41-56.

[3] Baker, R. S., Bloom, N. and S. J., Davis (2016). Measuring Economic Policy Uncertainty. Quarterly Journal of Economics, 131, 1593-1636.

[4] Basu, S., and Bundick, B. (2017). Uncertainty shocks in a model of effective demand. Econometrica, 85(3), 937-958.

[5] Baumeister, C. and Kilian, L. (2016), Lower oil prices and the U.S. economy: Is this time different?, Brookings Papers in Economic Activity, Fall 2016, 287-336.

[6] Bernanke, B. S. (1983). Irreversibility, uncertainty, and cyclical investment. Quarterly Journal of Economics, 98(1), 85-106.

[7] Bloom, N. (2009). The impact of uncertainty shocks. Econometrica, 77, 623-685.

[8] Bloom, N. (2014). Fluctuations in uncertainty. Journal of Economic Perspectives, 28, 2, 153-176

[9] Bloom, N., Bond, S., and Van Reenen, J. (2007). Uncertainty and investment dynamics. Review of Economic Studies, 74(2), 391-415.

[10] Bry, G., Boschan, C. (1971). Cyclical Analysis of Time Series: Selected Procedures and Computer Programs. NBER, New York.

[11] Byrne, J. P., Fazio, G., and Fiess, N. (2013). Primary commodity prices: Co-movements, common factors and fundamentals. Journal of Development Economics, 101, 16-26.

[12] Caggiano, G., Castelnuovo, E., and Groshenny, N. (2014). Uncertainty shocks and unemployment dynamics in US recessions. Journal of Monetary Economics, 67, 78-92.

[13] Caldara, D., Fuentes-Albero, C., Gilchrist, S., and Zakrajšek, E. (2016). The macroeconomic impact of financial and uncertainty shocks. European Economic Review, 88, 185-207.

[14] Carrière-Swallow, Y., and Céspedes, L. F. (2013). The impact of uncertainty shocks in emerging economies. Journal of International Economics, 90(2), 316-325.

[15] Delle Chiaie, S., Ferrara, L., and Giannone, D. (2021). Common factors of commodity prices. Journal of Applied Econometrics, forthcoming

[16] Drechsel, T., and Tenreyro, S. (2018). Commodity Booms and Busts in Emerging Economies. Journal of International Economics, 112, 200-218.

[17] Doz C., D. Giannone and L. Reichlin (2011). A two step estimator for large approximate dynamic factor models based on Kalman filtering. Journal of Econometrics, 164, 188-205.

[18] Elder, J. (2018). Oil price volatility: Industrial production and special aggregates. Macroeconomic Dynamics, 22(3), 640-653

[19] Elder, J., and Serletis, A. (2010). Oil price uncertainty. Journal of Money, Credit and Banking, 42(6), $1137-1159$.

[20] Fama, E. F., and French, K. R. (1988). Business cycles and the behavior of metals prices. Journal of Finance, 43(5), 1075-1093.

[21] Feng, L., Li, Z., and Swenson, D. L. (2017). Trade policy uncertainty and exports: Evidence from China's WTO accession. Journal of International Economics, 106, 20-36.

[22] Ferderer, J. P., 1996. Oil price volatility and the macroeconomy. Journal of Macroeconomics, 18(1), 1-26

[23] Fernández, A., Schmitt-Grohé, S., and Uribe, M. (2017). World shocks, world prices, and business cycles: An empirical investigation. Journal of International Economics, 108, S2-S14.

[24] Fernández, A., González, A., and Rodriguez, D. (2018). Sharing a ride on the commodities roller coaster: Common factors in business cycles of emerging economies. Journal of International Economics, 111, 99-121. 
[25] Forni, M., L. Gambetti and L. Sala (2021). Downside and upside uncertainty shocks, CEPR WP.

[26] Frankel, J.A. (2008). The Effect of Monetary Policy on Real Commodity Prices. in J. Y. Campbell: Asset Prices and Monetary Policy, pp. 291-333. University of Chicago Press.

[27] Frankel, J.A., and A.K., Rose. (2010). Determinants of Agricultural and Mineral Commodity Prices. In Inflation in an era of Relative Price Shocks. Reserve Bank of Australia.

[28] Gervais, A. (2018). Uncertainty, Risk aversion and International Trade. Journal of International Economics, 115, 145-158.

[29] Gruber, J. and R. Vigfusson (2018). Interest rates and the volatility and correlation of commodity prices, Macroeconomic Dynamics, 22(3), 600-619.

[30] Guo, H., and Kliesen, K. L. (2005). Oil price volatility and US macroeconomic activity. Review-Federal Reserve Bank of Saint Louis, 87(6), 669.

[31] Hamilton, J. (2014). Oil prices as an indicator of global economic conditions. Econbrowser Blog, December 2014.

[32] Handley, K. (2014). Exporting under trade policy uncertainty: Theory and evidence. Journal of international Economics, 94(1), 50-66.

[33] Handley, K., and Limao, N. (2015). Trade and investment under policy uncertainty: theory and firm evidence. American Economic Journal: Economic Policy, 7(4), 189-222.

[34] Handley, K., and Limao, N. (2017). Policy uncertainty, trade, and welfare: Theory and evidence for China and the United States. American Economic Review, 107(9), 2731-83.

[35] Huang, D., and Kilic, M. (2019). Gold, platinum, and expected stock returns. Journal of Financial Economics, 132(3), 50-75.

[36] Jo, S. (2014). The effects of oil price uncertainty on global real economic activity. Journal of Money, Credit and Banking, 46(6), 1113-1135.

[37] Jurado, K., S. Ludvigson, and S. Ng (2015). Measuring Uncertainty. American Economic Review, 105(3), $1177-1215$.

[38] Kilian, L. (2009). Not all oil price shocks are alike: Disentangling demand and supply shocks in the crude oil market. American Economic Review, 99(3), 1053-69.

[39] Kose M. A, C. Otrok, and C.H. Whiteman (2003). International Business Cycles: World, Region, and Country-Specific Factors. American Economic Review, 93(4), 1216-1239.

[40] Labys, W. C., Achouch, A., and Terraza, M. (1999). Metal prices and the business cycle. Resources Policy, 25(4), 229-238.

[41] Leduc, S., and Liu, Z. (2016). Uncertainty shocks are aggregate demand shocks. Journal of Monetary Economics, 82, 20-35.

[42] Marmer, V. and M. Slade (2018). Investment and uncertainty with time to build: Evidence from entry into U.S. copper mining. Journal of Economic Dynamics and Control, 95, 233-254.

[43] Miranda-Agrippino S. and H. Rey (2020). U.S. Monetary Policy and the Global Financial Cycle. Review of Economic Studies, 87(6), 2754-2776.

[44] Mohn K. and B. Misund (2009). Investment and uncertainty in the international gas and oil industry. Energy Economics, 31, 240-248.

[45] Novy, D., and Taylor, A. M. (2020). Trade and uncertainty. Review of Economics and Statistics, 102(4), 749-765.

[46] Piffer, M., and Podstawski, M. (2018). Identifying uncertainty shocks using the price of gold. Economic Journal, 128(616), 3266-3284.

[47] Pindyck, R. S. (1990). Irreversibility, uncertainty, and investment. NBER Working Paper No. 3307

[48] Pindyck, R. S. (2004). Volatility and commodity price dynamics. Journal of Futures Markets, 24(11), 1029-1047. 
[49] Pindyck, R. S., and Rotemberg, J.J. (1990). The Excess Co-Movement of Commodity Prices. Economic Journal, 100 (403), 1173-1189

[50] Punzi, M. T. (2019). The impact of energy price uncertainty on macroeconomic variables, Energy Policy, 129, 1306-1319.

[51] Poncela, P., Senra, E., and Sierra, P. (2020). Global vs sectoral factors and the impact of the financialization in commodity price changes. Open Economies Review, 31 (4), 859-879.

[52] Scotti, C. (2016). Surprise and Uncertainty Indexes: Real-Time Aggregation of Real-Activity MacroSurprises. Journal of Monetary Economics, 82, 1-19.

[53] Segal, G., I. Shaliastovich and Y. Amir, (2015). Good and Bad Uncertainty: Macroeconomic and Financial Market Implication. Journal of Financial Economics, 117, 369-397.

[54] Tam, P. S. (2018). Global trade flows and economic policy uncertainty. Applied Economics, 50(34-35), 3718-3734.

[55] Tran, T. D. (2021). The macroeconomic effects of commodity price uncertainty. CAMA, Crawford School of Public Policy, Working Paper 09/2021, Australian National University. 


\section{ANNEX}

Figure 11: Investment (INV) responses to exogenous GLUN shocks by country Responses of advanced economies INV to exogenous GLUN shock Responses of emerging economies INV to exogenous GLUN shock
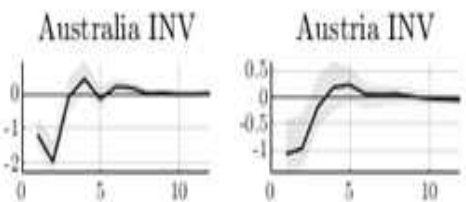

Canada INV

Argentina INV
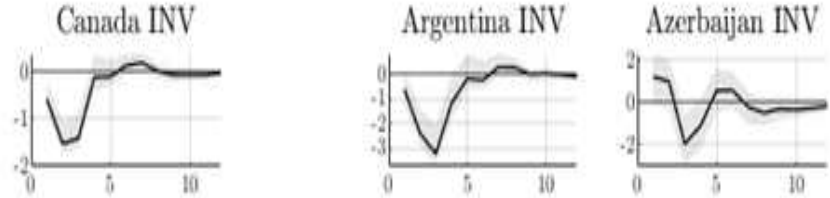

Brazil INV

Deumark INV

France INV

Colombia INV
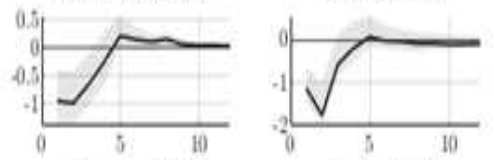

Germany INV

Georgia INV
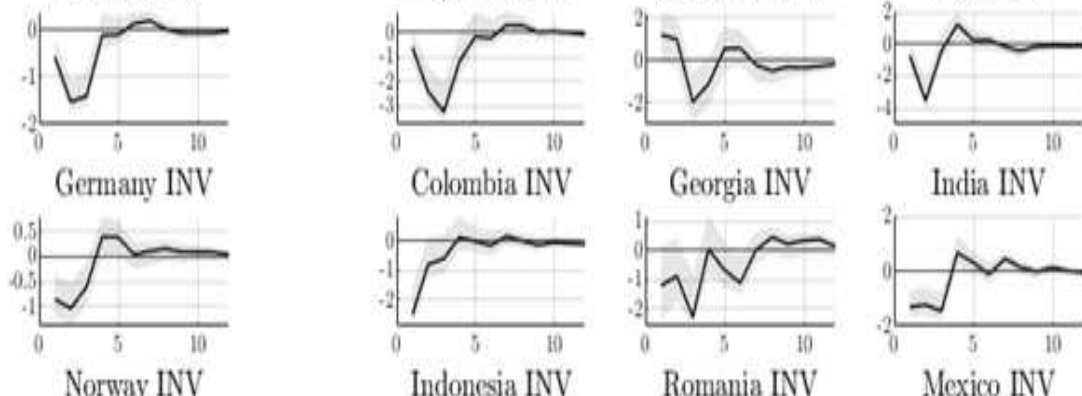

Greece INV

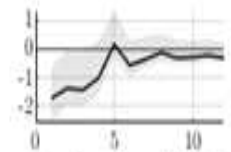

Italy INV

Norway INV
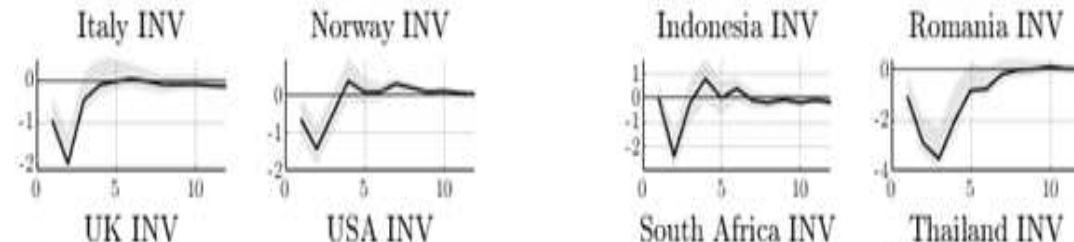

India INV
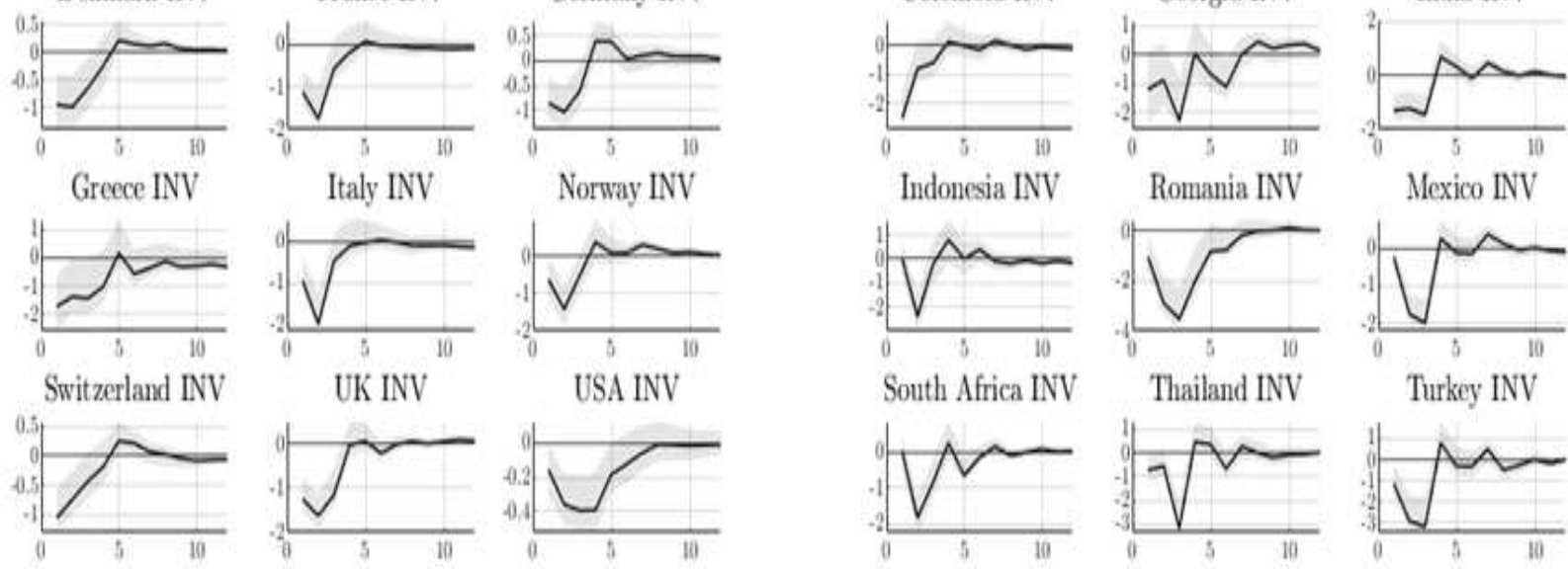

Turkey INV

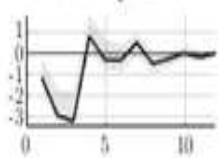

Note: The solid line shows the estimated IRFs (expressed in \%), while the shaded area shows the 68\% bootstrapped confidence intervals using 1000 repetitions. 
Figure 12: Exports (EXP) responses to exogenous GLUN shocks by country

Responses of adranced economies EXP to exogenous GLUN shock
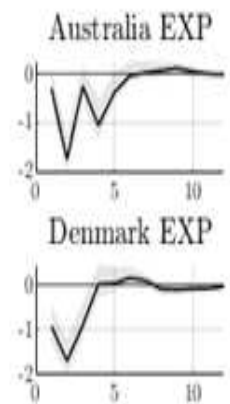

Grece EXP

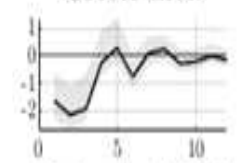

Switzerland EXP

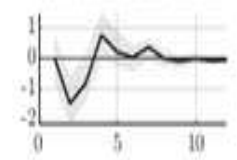

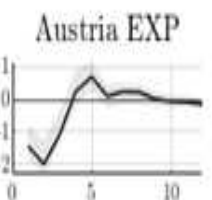

France EXP

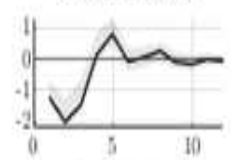

Italy EXP

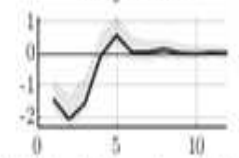

United Kingdom EXP United States EXP

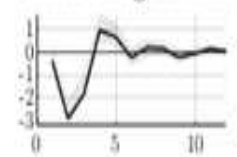

Canada EXP

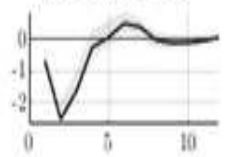

Germany EXP

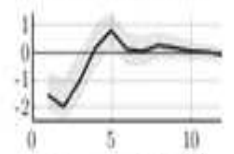

Norway EXP

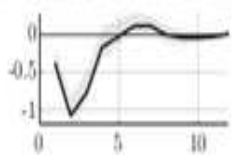

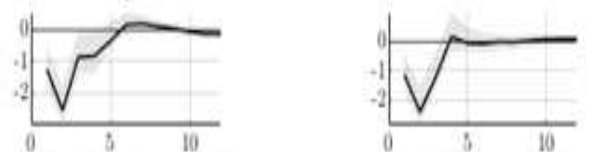

South Africa EXP
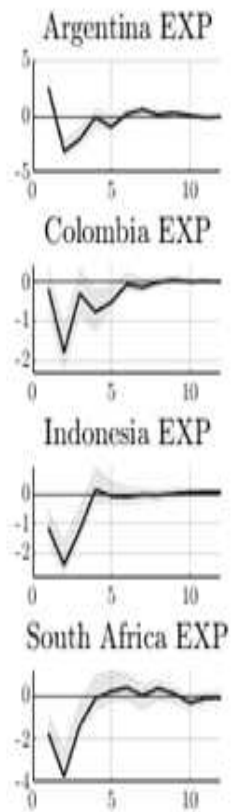

Responses of emerging economies EXP to exogenous GLUN shock

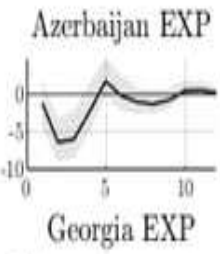

Brazil EXP

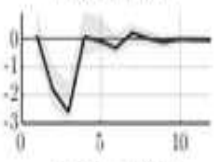

India EXP
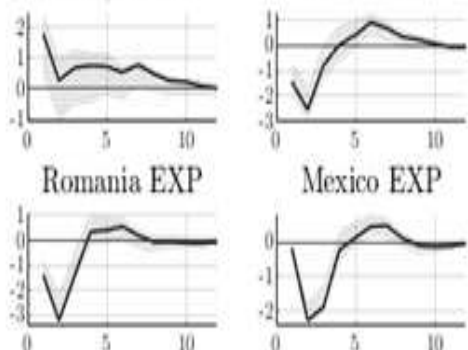

Thailand EXP
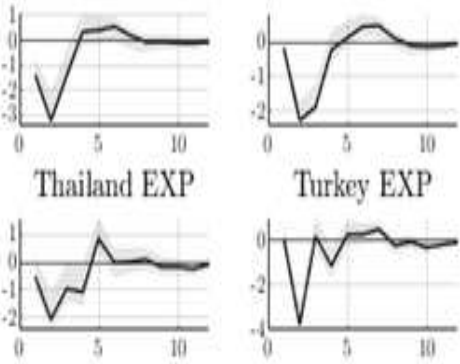

Note: The solid line shows the estimated IRFs (expressed in \%), while the shaded area shows the 68\% bootstrapped confidence intervals using 1000 repetitions. 
Figure 13: Investment (INV) responses to exogenous agricultural uncertainty (AGUN) shocks by country

Responses of advanced economies INV to exogenous AGUN shock

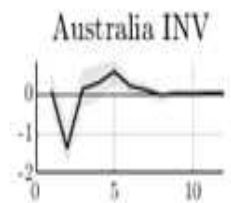

Deumark INV

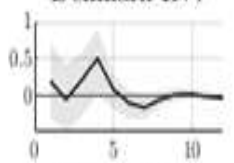

Greece INV

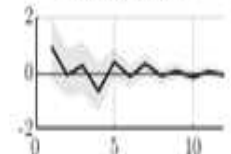

Switzerland INV

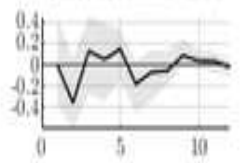

Austria INV

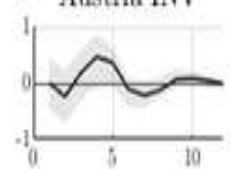

France INV

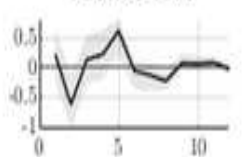

Italy INV

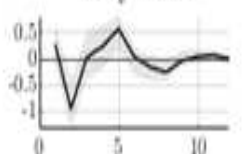

UK INV

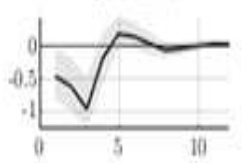

Canada INV

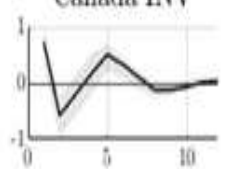

Germany INV

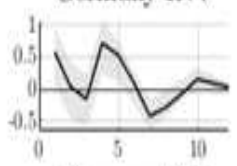

Norway INV

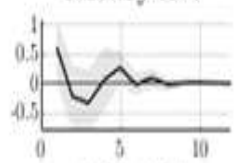

USA INV

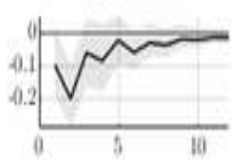

Responses of emerging economies INV to exogenous AGUN shock
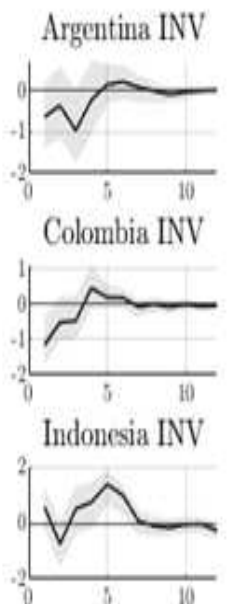

South Africa INV

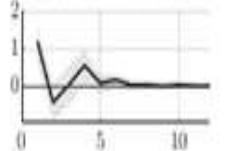

Azerbajjan INV

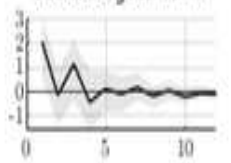

Georgia INV

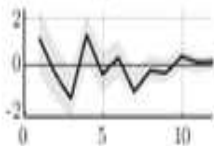

Romania INV

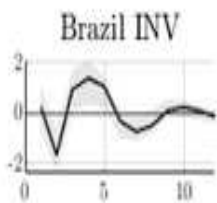

India INV

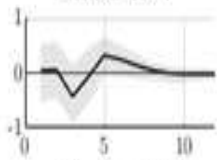

Mexico INV

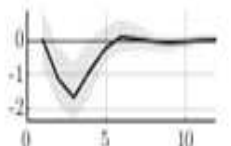

Thailand INV

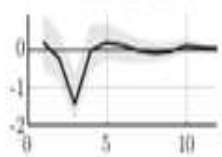

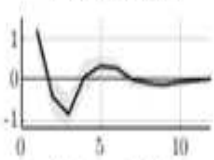

Turkey INV

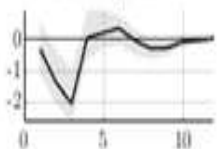

Note: The solid line shows the estimated IRFs (expressed in \%), while the shaded area shows the 68\% bootstrapped confidence intervals using 1000 repetitions. 
Figure 14: Investment (INV) responses to exogenous energy uncertainty (ENUN) shocks by country

Responses of advanced economies INV to exogenous ENUN shock

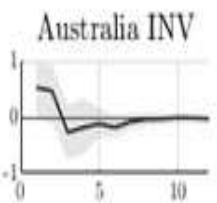

Deumark INV
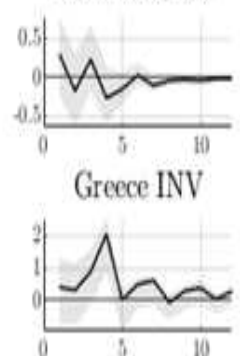

Switzerland INV

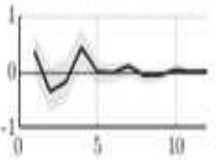

\section{Austria INV}

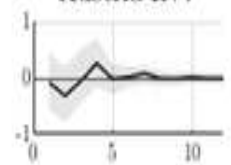

France INV

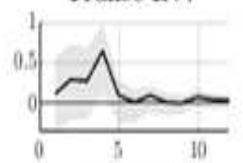

Italy INV

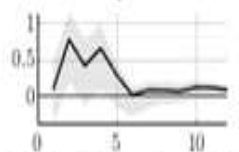

United Kingdom INV

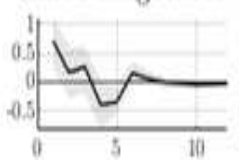

Canada INV

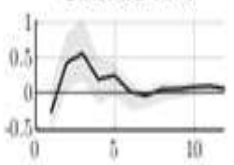

Germany INV

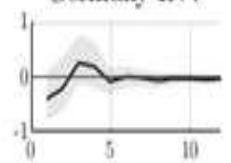

Norway INV

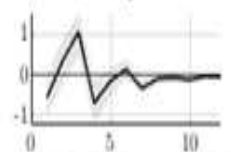

V United States INV

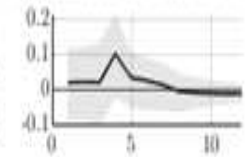

Responses of emerging economies INV to exogenous ENUN shock
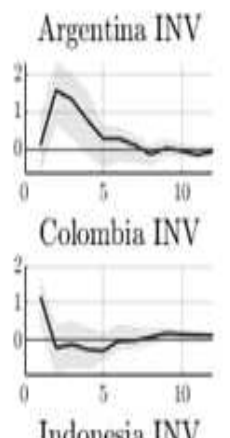

Azerbajjan INV

Brazil INV

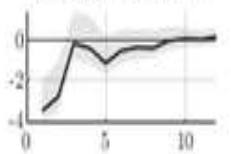

Georgia INV
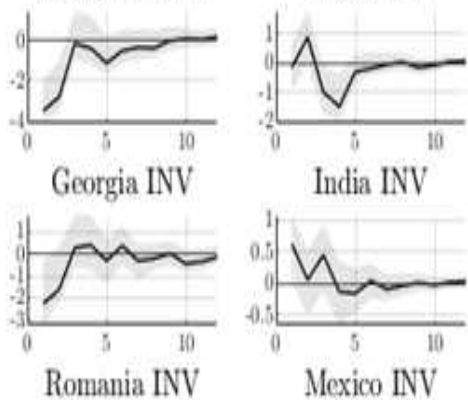

India INV
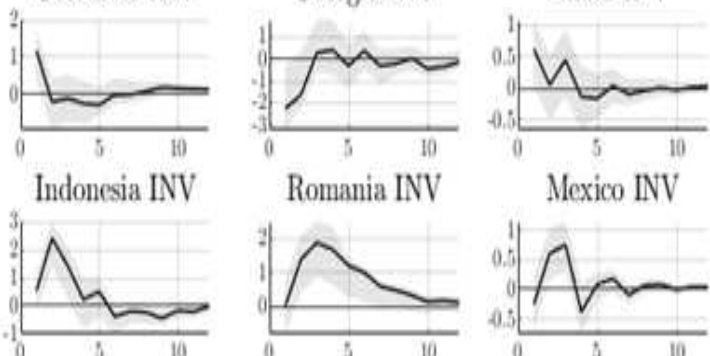

South Africa INV
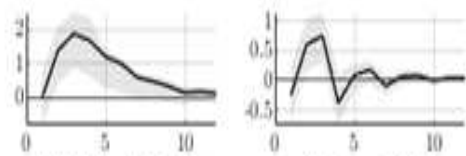

Thailand INV

Turkey INV
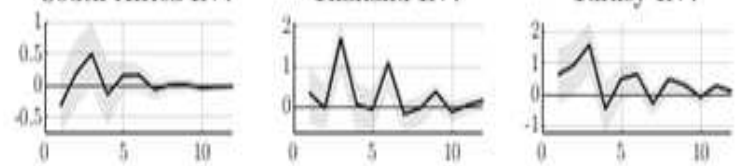

Note: The solid line shows the estimated IRFs (expressed in \%), while the shaded area shows the 68\% bootstrapped confidence intervals using 1000 repetitions. 
Figure 15: Investment (INV) responses to exogenous metals' uncertainty (MTUN) shocks by country

Responses of advanced economies INV to exogenous MTUN shock

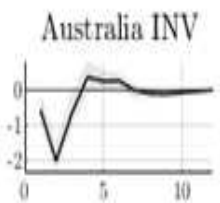

Deumark INV

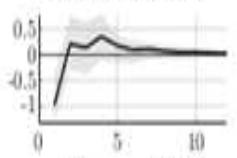

Greece INV

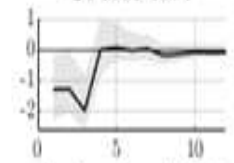

Switzerland INV

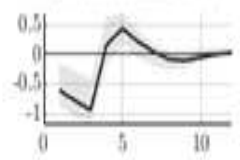

\section{Austria INV}

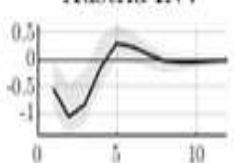

France INV

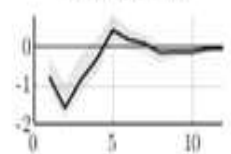

Italy INV

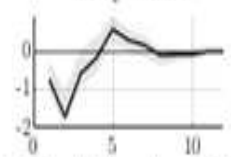

United Kingdom INV

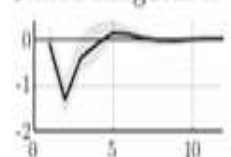

Canada INV

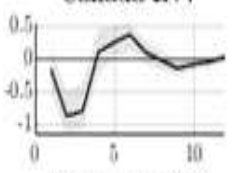

Germany INV

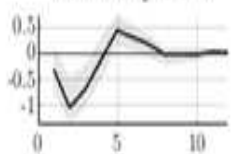

Norway INV

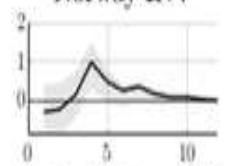

United States INV

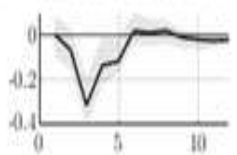

Responses of emerging economies INV to exogenous MTUN shock
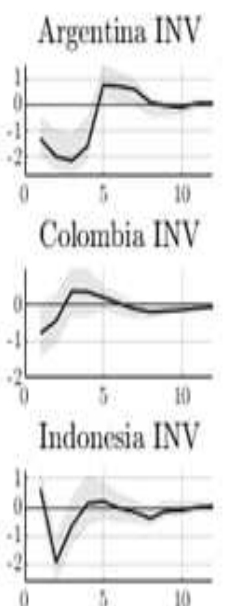

South Africa INV

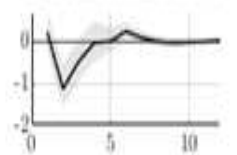

Azerbaijan INV

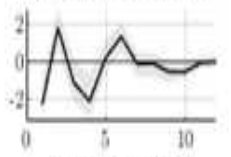

Georgia INV

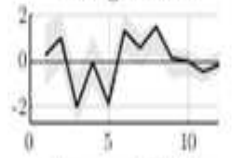

Romania INV

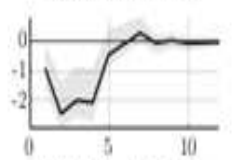

Thailand INV

Brazil INV

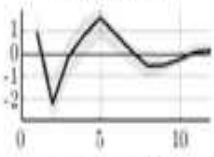

India INV

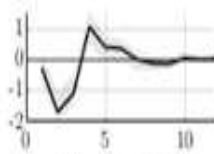

Mexico INV

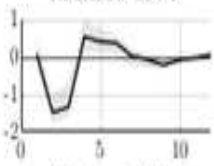

Turkey INV
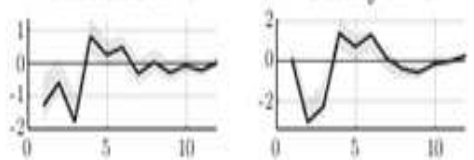

Note: The solid line shows the estimated IRFs (expressed in \%), while the shaded area shows the 68\% bootstrapped confidence intervals using 1000 repetitions. 